\title{
Enhancement of Dielectric Responses and Conduction Properties of Zn-doped TiO2 for Energy Storage and Photosensitivity Applications
}

\section{Mariem Dhaou}

Faculty of Sciences of Sfax: Universite de Sfax Faculte des Sciences de Sfax

\section{Elimame Elaloui}

University of Gafsa Faculty of Sciences of Gafsa: Universite de Gafsa Faculte des Sciences de Gafsa

\section{Kamel Khirouni}

University of Gabes Faculty of Sciences of Gabes: Universite de Gabes Faculte des Sciences de Gabes

\section{Hajer Guermazi}

Faculty of Sciences of Sfax: Universite de Sfax Faculte des Sciences de Sfax

\section{Samir GUERMAZI ( $\nabla$ samir.guermazi@ipeis.rnu.tn )}

Faculty of Sciences of Sfax: Universite de Sfax Faculte des Sciences de Sfax https://orcid.org/00000002-1896-3433

\section{Research Article}

Keywords: TiO2, Dielectric permittivity, Impedance spectroscopy, gap energy, Photocatalysis

Posted Date: February 25th, 2021

DOI: https://doi.org/10.21203/rs.3.rs-238079/v1

License: (c) (i) This work is licensed under a Creative Commons Attribution 4.0 International License. 


\title{
Enhancement of dielectric responses and conduction properties of $\mathrm{Zn}$-doped $\mathrm{TiO}_{2}$ for Energy Storage and Photosensitivity Applications
}

\author{
Mariem dhaou $^{1,2}$, Elimame Elaloui ${ }^{1}$, Kamel Khirouni ${ }^{3}$, Hajer Guermazi², Samir Guermazi ${ }^{2}{ }^{*}$ \\ ${ }^{1}$ Research Unit: Materials Environment and Energy (UR14ES26), Science Faculty Sidi Ahmed Zaroug 2112 \\ Gafsa, Tunisia. \\ ${ }^{2}$ Laboratory of Materials for Energy and Environment, and Modelling, Faculty of Science, University of Sfax, \\ 3000 Sfax, Tunisia. \\ ${ }^{3}$ Laboratory of Physics of Materials and Nanomaterials applied to Environment, Faculty of science University \\ of Gabes, Tunisia.
}

\begin{abstract}
This work deals with the physical investigations on $\mathrm{Zn}$-doped $\mathrm{TiO}_{2}$ synthesized via a solvent controlled nonaqueous sol-gel route. X-ray diffraction analysis indicated that $\mathrm{TiO}_{2}$ particles crystallized in both tetragonal anatase and rutile structures. FTIR analysis confirmed the insertion of $\mathrm{Zn}$ in $\mathrm{TiO}_{2}$ network, and revealed the presence of surface defects in the prepared powders, as proved by their porous morphologies. UV-visible absorption was performed to provide an insight into the band-gap variation in the $\mathrm{Zn}$-doped $\mathrm{TiO}_{2}$ nanopowders as a function of $\mathrm{Zn}$ doping. On the other hand, the electrical properties were studied using complex impedance spectroscopy in the frequency range from $40 \mathrm{~Hz}$ to $1 \mathrm{MHz}$ at temperature range $480-600 \mathrm{~K}$. The impedance plots are well fitted to an $\left(\mathrm{R}_{1} / / \mathrm{C}_{1}\right)-\left(\mathrm{R}_{2} / / \mathrm{CPE}_{1}\right)$ equivalent circuit. As well, the correlated barrier hopping model $(\mathrm{CBH})$ was proposed to describe the conduction mechanism. Finally, Photocatalytic activities of the $\mathrm{Zn}$ doped $\mathrm{TiO}_{2}$ nanoparticles were evaluated via the degradation of the rhodamine $\mathrm{B}(\mathrm{RhB})$ dye under UV light irradiation. The results showed enhanced performance by Zn-doping, compared to the undoped $\mathrm{TiO}_{2}$ nanoparticles.
\end{abstract}

KEYWORDS: $\mathrm{TiO}_{2}$; Dielectric permittivity; Impedance spectroscopy; gap energy, Photocatalysis.

\section{Declarations}

The authors declare that they have no known competing financial interests or personal relationships that could have appeared to influence the work reported in this paper.

Funding : This research was supported by the Tunisian Ministry of High Education and Scientific Research Conflicts of interest/Competing interests: No Conflicts of interest

Availability of data and material (data transparency)

Code availability: Not applicable

Authors' contributions:

Mariem dhaou: Conceptualization, Methodology, Software, Writing- Original draft preparation.

Kamel Khirouni:Dielectric measuraments

Hajer Guermazi: Visualization, Investigation, Writing- Reviewing.

Elimame Elaloui: Visualization, Validation, Supervision, Writing- Reviewing

Samir Guermazi: Writing- Reviewing and Editing, Validation, Supervision

Ethics approval (include appropriate approvals or waivers)

Consent to participate (include appropriate statements): Not applicable

Consent for publication (include appropriate statements): Not applicable

\footnotetext{
*Corresponding author : e-mail: samir.guermazi@gmail.com
} 


\section{Relevance Summary:}

This paper is an original work entitled "Enhancement of dielectric responses and conduction properties of $\mathrm{Zn}$ doped TiO2 for Energy Storage and Photosensitivity Applications"

Z $\mathrm{Zn}$ doped $\mathrm{TiO} 2$ powders consist on a mixture of rutile and anatase crystalline phases.

The powder morphology is highly affected by $\mathrm{Zn}$ doping. It leads to the formation of nanosheets

0 the conduction mechanism is dominated by the correlated barrier hopping model

0 the capacitive behavior of $\mathrm{TiO}_{2}$ is improved by $\mathrm{Zn}$ doping

$3 \%$ mol $\mathrm{Zn}$ doped $\mathrm{TiO}_{2}$ is promising photocatalyst for the degradation of $\mathrm{RhB}$ pollutant as a model

\section{Acknowledgements}

Authors gratefully thank the financial support of the Tunisian Ministry of High Education and Scientific Research.

\section{Introduction}

Titanium oxide $\mathrm{TiO}_{2}$ has been widely investigated thanks to its good thermal, physical, and electrical performances. It is a n-type semi-conductor having a wide band gap energy of $3.2 \mathrm{eV}$ at room temperature [1]. Also, it has a relatively high refractive index and dielectric permittivity [2], making it promising for various applications, such as: positive electrode in batteries, transparent conducting electrodes in photovoltaic devices, gas sensors and photocatalytic degradation of organic dyes for water and air purification, self-cleaning surfaces, and antibacterial activity[3-6]. Several physical and chemical methods have been used to prepare $\mathrm{TiO}_{2}$ nanoparticles and thin films, such as co-precipitation [7-8], polyol method [9], RF sputtering [10], chemical vapor deposition (CVD) [11], pulsed laser deposition [12] and spray pyrolysis [13]. Moreover, many efforts have been conducted to obtain nanopowders with desirable physical and/or chemical properties. Among the preparation techniques, solgel is cost-effective. It has many advantages such as homogeneity, lower crystallization temperature, a relatively chemical purity of powders and self-limiting surface reactions. Commonly, $\mathrm{TiO}_{2}$ contains different types of defects, due to oxygen vacancies [14], oxygen interstitial[15], Ti vacancies [16], Ti interstitial [17] and more complex defects [18]. Defects can also be monitored via appropriate substitution doping. Many works reported that small concentrations of doping metals such as $\mathrm{Ta}, \mathrm{Al}, \mathrm{Yb}, \mathrm{Nb}$, In, Sn and Fe can significantly affect the electrical, dielectric properties of $\mathrm{TiO}_{2}$ [19-23]. This enhanced the charge storage mechanism by introducing more oxygen in $\mathrm{TiO}_{2}$ network, which in turn creates additional energy levels in the band gap of $\mathrm{TiO} 2$. In addition, the surface morphology takes a leading role. Thus, porous, interconnected, conducting materials and materials with high surface to volume ratio such as nanocrystals can offer high specific capacitance value. To date, many researches have been focused on nanostructured $\mathrm{TiO}_{2}$ (thin films, powders, nanocomposites, ...) and it was reported that their morphology plays a crucial role in dielectric properties due to their large surface area [24]. In this context, the exploration of the dielectric properties of the material is one of current research topics, as it can predict whether the material is a promising candidate for energy storage application. As well, many studies on photoactivity of $\mathrm{TiO}_{2}$ oxide have been reported since the early of the 20th century. Indeed, it was reported that UV absorption may produce active oxygen species on $\mathrm{TiO}_{2}$ surface causing the photo-bleaching of dyes. Recently, ultrafine nanoparticles of $\mathrm{TiO}_{2}$ have been synthesized. These nanoparticles exhibit a noticeably photodegradation efficiency in visible light of methylene blue (MB) dye and completely photoreduction of $\mathrm{Cr}^{4+}$ ions [25]. In the same line, $\mathrm{Mn}-\mathrm{Zn}$ co-doped $\mathrm{TiO}_{2}$, synthesized by a simple step sonochemical route without annealing treatment process showed a relatively high photocatalytic degradation performance of rhodamine B $(\mathrm{RhB})$ dye under visible light [26]. Herein, besides the synthetic protocol and the physical investigations of $\mathrm{Zn}$ doped $\mathrm{TiO}_{2}$ nanopowders, a specific emphasis is put on their photocatalytic properties against $(\mathrm{RhB})$ dye under UV illumination.

\section{Experimental Details}

\subsection{Material Preparation}


Undoped and $1 \mathrm{~mol} \%, 2 \mathrm{~mol} \%$ and $3 \mathrm{~mol} \% \mathrm{Zn}$-doped $\mathrm{TiO}_{2}$ were synthesized via the sol-gel process. For that, given amounts of $\mathrm{Ti}(\mathrm{OPr})_{4}$ and ethanol, in (2:3) ratio were mixed in a glass container. After the complete mixing, glacial acetic acid was slowly added to the resultant homogeneous yellow solution in order to promote the acid hydrolysis at $\mathrm{pH}=3$. In all obtained samples, a stoichiometric amount of commercial Zinc acetate $(\mathrm{ZnC} 4 \mathrm{H} 6 \mathrm{O} 4$, Aldrich) was introduced after 60 min of stirring to obtain $\mathrm{Zn}$-doped $\mathrm{TiO}_{2}$. Thus, obtained sols were stirred, capped and kept at ambient conditions for more than 24 hours, in order to complete the gelation step, after which transparent xerogels (monoliths) were obtained. We proceeded to heat treatment of these powders. Firstly, they were dried at $110{ }^{\circ} \mathrm{C}$ for 12 hours, then annealed at $500{ }^{\circ} \mathrm{C}$ for 5 hours to obtain a thermally stable crystalline phase. The gelation time for undoped $\mathrm{TiO}_{2}$ was $60 \mathrm{~min}$ while for $\mathrm{Zn}$-doped $\mathrm{TiO}_{2}$, the gelation needed more much time (about15 days).

\subsection{Characterization techniques}

First, X-ray diffraction (XRD) patterns were recorded to characterize the phase and crystal structure of nanoparticles using a Phillips powder diffractometer operating with copper K $\alpha$ radiation source $(\lambda=1.54056 \AA)$ over a wide range of Bragg angles $\left(10^{\circ}<2 \theta<60^{\circ}\right)$. Also, the structural analysis was carried out using the standard Rietveld method [27]. The morphology of the $\mathrm{TiO}_{2}$ powders was analyzed by a Hitachi S4100-1 scanning electron microscope (SEM). Second, Fourier transformed infrared (FTIR) analysis was carried out using Perkin Elmer spectrometer in the wavenumber range of $400-4000 \mathrm{~cm}^{-1}$. The optical absorption measurements of the powders were recorded using a Shimadzu UV-3101 PC spectrophotometer in the UV-visible range (from 200 to $2000 \mathrm{~nm}$ wavelength). On the other hand, the electrical properties of $\mathrm{TiO}_{2}$ nanoparticles calcined at $500^{\circ} \mathrm{C}$ were investigated using the impedance spectroscopy [28]. Prior to measurements, the $\mathrm{TiO}_{2}$ powders were pressed into pellets of 8 $\mathrm{mm}$ diameter and $1 \mathrm{~mm}$ thickness to form a plate capacitor configuration. Aluminum films of $6 \mathrm{~mm}$ in diameter were deposited on both sides of the pellet. Afterwards, electrical impedances were measured using a Tegam $3550 \mathrm{ALF}$ impedance analyzer operating over a frequency range $40 \mathrm{~Hz}-1 \mathrm{MHz}$ and at temperature $480-600 \mathrm{~K}$. Finally, the photocatalytic degradation experiments were carried out by monitoring the evolution of the main absorption of $\mathrm{RhB}$ aqueous solution $(\lambda \max =554 \mathrm{~nm})$ after irradiation with UV light for 10 to $140 \mathrm{~min}$. The absorbance spectra were recorded by means of Shimadzu UV3100 spectrophotometer, using a high-pressure mercury lamp $(300 \mathrm{~W})$ as a light source. Before illumination, the solution was magnetically stirred for $60 \mathrm{~min}$ (in dark), in order to ensure an adsorption equilibrium between the sample surface and the organic dye [29]. A detailed description of the photocatalytic reactor was previously reported [30, 31]. The $\mathrm{RhB}$ dye photodegradation efficiency $(\eta)$ was calculated for the main absorption of RhB solution as follows [32 ]:

$$
\eta(\%)=\left(1-\mathrm{C} / \mathrm{C}_{0}\right) \times 100
$$

where $\mathrm{C}$ is the $\mathrm{RhB}$ dye concentration at time $\mathrm{t}$ of the reaction and $\mathrm{C}_{0}$ is the concentration of the initial dye solution $\left(\mathrm{C}_{0}=30 \mathrm{mg} / \mathrm{l}\right)$, deduced from: $\mathrm{C} / \mathrm{C}_{0}=\mathrm{A} / \mathrm{A}_{0}$ ( $\mathrm{A}$ is the absorbance of the $\mathrm{RhB}$ dye solution).

\section{Results and discussions}

\subsection{Structural analysis}

Fig.1 shows the XRD patterns of undoped and zinc-doped titanium dioxide nano-powders as a function of $\mathrm{Zn}$ content. The diffraction peaks in all samples matched well with the typical anatase (A) and rutile (R) phases of tetragonal $\mathrm{TiO}_{2}$. Besides, in $3 \mathrm{~mol} \% \mathrm{Zn}$ doped $\mathrm{TiO}_{2}$ sample, a small trace of brookite phase was formed, confirmed by the characteristic (200) peak. All the diffraction peaks agreed with the JCPDS cards (153-0152 for anatase, 
900-7532 for rutile and 900-4139 for brookite phases). No additional peaks characteristic of secondary phases such as zinc oxide were detected.

Moreover, specific surface area $\left(S_{a}\right)$, was estimated for all the samples using the following equation:

$$
S_{a}=6 /(D \rho)
$$

where $\mathrm{D}$ is the average crystallite size estimated according to Scherrer model. $\rho$ is the density of samples calculated by the following relation [33]:

$$
\rho=n M / N V
$$

where $n=4$ for anatase and $n=2$ for rutile phase, $M$ is molecular weight, $N$ is Avogadro's number and $V$ is the unit cell volume.

The obtained values are listed in Table 1. The density $(\rho)$ of all the samples was found to have almost the same value (about $3.9 \mathrm{~g} / \mathrm{cm}^{3}$ for anatase phase and about $4.25 \mathrm{~g} / \mathrm{cm}^{3}$ for rutile phase), while the specific surface area increased with the increase of doping concentration. This may be attributed to the decrease of the crystallite size. In fact, we noticed, from Fig.2, that $\mathrm{Zn}$ doped samples have larger specific surface area, which is promising for high photocatalytic efficiency. This will be confirmed in the following sections.

\subsection{SEM observations}

The surface morphology was shown in Fig. 3(a, b) for undoped and 1 mol $\% \mathrm{Zn}$ doped $\mathrm{TiO}_{2} \mathrm{NPs}$ as an example. One can clearly notice changes in shape and size of $\mathrm{TiO}_{2}$ nanoparticles with doping. The SEM micrographs revealed the presence of a small irregularly spherical and slightly elongated morphology of the undoped $\mathrm{TiO}_{2}$ particles with an average particle size in the range of $140 \mathrm{~nm}$. However, $\mathrm{Zn}$ doped nanopowders exhibit randomly distributed 2D nanosheets with a nanometric thickness.

Furthermore, the porous texture of these samples was not uniform and it is obviously doping dependent. It is clear that both macropores and mesopores were included and interconnected. This porous morphology would lead to an enhancement in photocatalytic activities of $\mathrm{Zn}$ doped $\mathrm{TiO}_{2}$ nanopowders.

\subsection{FTIR Spectroscopy}

FTIR spectra of all samples are displayed in Fig 4. The broad band located around $3450 \mathrm{~cm}^{-1}$ was attributed to the stretching vibration mode $(\mathrm{v}(\mathrm{OH}))$ originated from the adsorbed water [34]. The later was confirmed by the band around $1622 \mathrm{~cm}^{-1}$ attributed to the bending vibrations of $\mathrm{H}-\mathrm{O}-\mathrm{H}(\delta(\mathrm{OH}))$ [35]. Indeed, the porous surface morphology proved by SEM images facilitate the water adsorption at the surface of $\mathrm{TiO}_{2}$ nanoparticles. Furthermore, the bands spread in the frequency domain between $\sim 500$ and $\sim 700 \mathrm{~cm}^{-1}$ are related to the presence of metal-oxygen bonds (Ti-O-Ti), (Ti-O, $\mathrm{Zn}-\mathrm{O})$ and (Ti-O-Zn) [36]. In addition, we noticed a change in the vibrational band shape with doping mainly for the sample with $3 \% \mathrm{Zn}$ doping. This can be related to the disorder created by the incorporation of $\mathrm{Zn}$ atoms in $\mathrm{TiO}_{2}$ network.

\subsection{UV-visible analysis}

In order to investigate the changes in optical transitions of $\mathrm{TiO}_{2} \mathrm{NPs}$ due to $\mathrm{Zn}$-doping, UV-visible absorption measurement was performed. The absorption spectra of the samples were computed from the diffuse reflectance spectra using the Kubelka-Munk equation (Fig. 5(a)). The absorption at around $285 \mathrm{~nm}$ corresponds to the electronic transition from $2 p$ state of oxygen atoms in the valence band, to the $3 \mathrm{~d}$ state of $\mathrm{Ti}$ in the conduction band [37]. Moreover, from this figure, it is noted that the UV light absorption increases with increasing Zn content, which may be due to sp-d exchange interactions between the electron band and the localized d-electrons of $\mathrm{Zn}^{2+}$ ions. 
The band gap energies Eg of the $\mathrm{Zn}$ doped $\mathrm{TiO}_{2}$ NPs were estimated from the Tauc's plots (Fig. 5(b)) according to the following formula [38]:

$$
\alpha h \vartheta=B(h \vartheta-E g)^{n}
$$

where $\alpha$ is the absorption coefficient given by $\alpha=2.303$ / A.d, with A is the absorbance and d is the thickness of the sample, $\mathrm{B}$ is a constant and ho is the photon energy. The exponent $\mathrm{n}$ value depends on the nature of the electronic transition. It is equal to $1 / 2$ for $\mathrm{TiO}_{2}$ as it is a direct band gap semiconductor [39]. The optical band gap was obtained by extrapolating the linear part of the curve to the ho-axis. Results showed a slight red-shift of the band gap of $\mathrm{Zn}$ doped $\mathrm{TiO}_{2}$ samples. It shifted from $3.37 \mathrm{eV}$ for undoped sample to $3.32 \mathrm{eV}$ for 3 mol\% $\mathrm{Zn}$ doped one (insert of Fig. 5(b)). The shrinkage of the band gap with increasing Zn doping can be explained by the introduction of new defect states in the band gap of $\mathrm{TiO}_{2}$. Indeed, doping induces a new band distribution relative to $\mathrm{Zn}^{2+}$ and oxygen vacancies, and consequently can narrow the band gap by forming a sallow level states below the conduction band [40].

\subsection{Impedance analysis}

The Nyquist plots (-Z” vs Z') of $\mathrm{TiO}_{2}$ samples as a function of temperature wre shown in Figs.6(a-d). At selected temperatures ranging from $480 \mathrm{~K}$ to $600 \mathrm{~K}$, the figures exhibit deformed semicircles. They indicated the existence of non-Debye relaxation phenomenon with distribution of relaxation times. Non Debye-like behavior of individual electro-active regions in the material can be modelled by a variety of circuit elements. The more common model is formed by combinations of resistance $(\mathrm{R})$ and constant phase element (CPE). The CPE component was proposed by Abram [41]. Its impedance is expressed by:

$$
\mathrm{Z}_{\mathrm{CPE}}=\left[\mathrm{Q}(\mathrm{j} \omega)^{\alpha}\right]^{-1}
$$

where $\mathrm{j}$ is the imaginary unit $\left(j^{2}=-1\right), \mathrm{Q}$ is a constant and $\alpha$ is a dimensionless parameter $(0<\alpha<1)$. It characterizes the degree of deviation from ideal Debye-like illustration [42].

The experimental data of Fig.6(a-d) are fitted using the Z-view software. So, the best fit of experimental data was obtained with an equivalent circuit that consists of two parallel combinations of resistance and CPE elements $\left(\mathrm{R}_{1} / / \mathrm{CPE}_{1}\right.$ in serial with $\left.\mathrm{R}_{2} / / \mathrm{CPE}_{2}\right)$ as presented in the inset of this figure. The equivalent circuit parameters estimated from the best fit of experimental data are gathered in Tables 2(a-d). These parallel combinations depicted the volume (grains) and interfacial (grain boundaries) effects. Therefore, the overlapped semicircles confirm the dispersal nature of the relaxations and the strong heterogenic nature of materials [43]. This result can be related to the existence of a mixture of anatase and rutile phases as detailed in XRD analysis section.

The $\alpha$ values are close to the unit, which implies the capacitive behavior of the $\mathrm{Zn}$ doped $\mathrm{TiO}_{2}$.

When increasing temperature, the low frequency intersection point of the diagrams with the $\mathrm{x}$-axis shifts towards the origin of the diagram indicating the decrease in the resistivity of the samples, assisted by the increase of the mobility of charge carriers thus the conduction process [44]. In addition, the presence of free charge carriers and impurities at the grain boundaries can influence the electrical conductivity. At high frequencies, the second semicircle is very weak, which indicates the dominance of the grain boundary contributions in conductivity [45].

Fig. 7 shows the variation of real part $\left(Z^{\prime}\right)$ of impedance as the function of frequency at different temperatures for the all $\mathrm{TiO}_{2}$ samples. It is found that the magnitude of $\mathrm{Z}^{\prime}$ decreases smoothly with the increase in both frequency and temperature (i.e., NTCR behavior). The decrease of Z' values for the selected temperatures may be due to release of space charges with the increase of frequency. The coincidence of the $Z^{\prime}$ values at high frequency side at all temperatures confirms the concept of space charge effect [46]. Furthermore, the effect of doping on the 
resistivity can be cleared through the analysis of the values of $Z^{\prime}$ at low frequencies at a given temperature. It is obvious that it increases by factor of about ten in $\mathrm{Zn}$ doped samples compared to undoped $\mathrm{TiO}_{2}$.

In order to understand the charge motion mechanism and the relaxation process as a function of temperature, the frequency dependence of imaginary part $\left(Z^{\prime \prime}\right)$ of the complex impedance was plotted at different temperatures (Fig. 8 a-d). The ( $\left.Z^{\prime \prime}\right)$ spectra clearly show relaxation peak which the frequency and intensity are strongly temperature dependent. Indeed, the relaxation peak shifts towards higher frequencies with increasing temperature, whereas $\left(Z^{\prime \prime}\right)_{\max }$ value decreases. This indicates a thermally activated dielectric relaxation process.

\subsection{Dielectric analysis}

The dielectric losses can be deduced from impedance components as follows:

$$
\varepsilon^{\prime \prime}=\frac{Z^{\prime}}{\omega C_{0}\left(Z^{\prime 2}+Z^{\prime \prime^{2}}\right)}
$$

Fig.9a-d displays the frequency dependence of the imaginary part of dielectric constant. The dielectric losses rise sharply at low frequencies, reach high values at high temperatures and decreases as frequency increases. The decrease in high frequencies is attributed to ionic inertia hindering the dipole to follow the frequency response. Thus, the dielectric losses approach a zero value. Furthermore, the charge carriers are trapped by defects in grain boundaries, forming dipole moments. Hence, the hopping of charge carriers between defect centers (Titanium interstitials and oxygen vacancies) at the grain boundaries constitutes the dielectric polarization at lower frequencies.

In the explored frequency range, $\varepsilon "(f)$ plots do not show any loss peaks, due to conduction phenomena or/and electrode polarization which may obscure a dielectric relaxation [47-50]. To overcome this difficulty, we used the electric modulus formalism, in which the electric modulus is defined as follows:

$$
M^{*}=\frac{1}{\varepsilon^{*}}
$$

\subsection{Electrical modulus analysis}

The complex electric modulus representation $M^{*}(\omega)$ developed by Provenzano et al. [51] is one of the methods to analyze the space charge relaxation phenomena which is not clearly detected, when the complex permittivity formalism is used. The electric modulus $\mathrm{M}^{*}$ is given by the following equation:

$$
M^{*}=\frac{1}{\varepsilon^{*}}=\frac{\varepsilon^{\prime}}{\varepsilon^{\prime 2}+\varepsilon^{\prime 2}}+j \frac{\varepsilon^{\prime \prime}}{\varepsilon^{\prime 2}+\varepsilon^{\prime \prime}}=M^{\prime}+j M^{\prime \prime}
$$

where $\mathrm{M}^{\prime}, \mathrm{M}^{\prime \prime}$ are the real and the imaginary parts of the electric modulus, and $\varepsilon^{\prime \prime}$ is expressed as:

$$
\varepsilon^{\prime \prime}=\frac{\left(\varepsilon_{s}-\varepsilon_{\infty}\right)(\omega \tau)^{1-\alpha} \sin \left(\frac{(1-\alpha) \pi}{2}\right)}{\left.1+2(\omega \tau)^{1-\alpha} \cos \left(\frac{(1-\alpha) \pi}{2}\right)+(\omega \tau)^{2(1-\alpha}\right)}+\frac{\sigma_{0}}{\varepsilon_{0} \omega}
$$

$\sigma_{0}$ is the static conductivity, $\alpha$ is a parameter between 0 and $1, \varepsilon_{\mathrm{s}}$ and $\varepsilon_{\square}$ are, respectively, the static and infinite frequency dielectric constants, $\omega$ is the angular frequency $(\omega=2 \pi \mathrm{f}), \tau$ is the relaxation time and $\varepsilon_{0}=8.8510^{-12} \mathrm{~F} / \mathrm{m}$ is the permittivity of vacuum.

As it can be seen, the electric modulus can greatly decline the electrode polarization and conduction effects, which appear to obscure relaxation in the permittivity presentation [52].

Fig.10. shows the variation of imaginary part of electric modulus $M$ ', with frequency at different temperatures. It exhibits a relaxation peak that shift toward the higher frequency side with an increase in temperature. This indicates a thermally activated behavior of the relaxation. 
The peak is assigned to the transition from long-range to short range mobility of charge carriers with the increase in frequency [53]. In fact, it is associated to the dipolar relaxation of the $\mathrm{TiO}_{2}$ grains [54, 55]. This peak is usually related to oxygen interstitial $\mathrm{O}_{\mathrm{i}}$, oxygen vacancy $\mathrm{V}_{\mathrm{O}}$, and titanium interstitial $\mathrm{Ti}_{\mathrm{i}}$. These observations are in good agreement with the results obtained by Ben Taher et al. [56]. Besides, the asymmetry in the relaxation peak indicates distribution of the relaxation time, and hence the relaxation in the material is of non-Debye type. Furthermore, it is obvious that $\mathrm{Zn}$ doped $\mathrm{TiO}_{2}$ exhibit more dispersive relaxation behavior vs temperature, compared to the undoped $\mathrm{TiO}_{2}$ (Fig. 10), due to structural disorder induced by insertion of $\mathrm{Zn}$ ions into $\mathrm{TiO}_{2}$ network.

\subsection{Conductivity study}

The ac conductivity $(\sigma)$ of the material can be calculated using the following relation:

$$
\sigma=\omega \varepsilon_{0} \varepsilon^{\prime \prime}
$$

The $(\sigma)$ plots of undoped and $\mathrm{Zn}$ doped $\mathrm{TiO}_{2}$ samples are displayed in Figs. 11(a-d). The conductivity is almost constant at low frequencies, then increases with the increase of frequency. At low frequencies, the frequency independent values of conductivity, corresponds to the dc conductivity. Moreover, an increase in $\sigma_{\mathrm{dc}}$ is noticed when increasing temperature. In fact, at low frequencies, few charge carriers can tunnel through the potential barrier at the grain boundaries, related with low conductivity. More charge carriers tunneling let to enhance the conductivity at higher temperatures and frequencies. Beyond a definite value of frequency, the charge carriers get sufficient energy to overcome the potential barrier and hence a rapid increase in conductivity occurs at higher frequencies [57]. Furthermore, it is clearly seen from Fig. 11(e) that dc conductivity sharply decreases in the doped samples from about $5.10^{-9} \Omega^{-1} \cdot \mathrm{cm}^{-1}$ in the undoped $\mathrm{TiO}_{2}$ to $7.10^{-10} \Omega^{-1} \cdot \mathrm{cm}^{-1}$ in $3 \% \mathrm{Zn}$ doped $\mathrm{TiO}_{2}$. This can be related to $\mathrm{Zn}^{2+}$ incorporated into a $\mathrm{TiO}_{2}$ lattice. Indeed, as their ionic radius are almost equal $\left(\mathrm{r}_{\mathrm{Ti}}{ }^{4+}=0.068 \mathrm{~nm}\right.$ and $\left.\mathrm{r}_{\mathrm{Zn}}{ }^{2+}=0.074 \mathrm{~nm}\right), \mathrm{Zn}$ can easily substitute Ti ions. Therefore, $\mathrm{Zn}$ ions causes defects like titanium interstitials and oxygen vacancies in the host $\mathrm{TiO}_{2}$ system, which act as deep charge traps [58], thus reduces the charge mobility and consequently decreases the conductivity. Furthermore, several reports $[59,60]$ approved that the dopants confined in interstitial sites can act as trapping or recombination centers for excited electrons and holes [61].

The ac conductivity can be described by the following equation:

$$
\sigma(\omega)=\sigma_{d c}+A \omega^{s}
$$

known as Jonscher's universal power law [62], where $A$ is a constant and $\mathrm{s}$ is a temperature and frequency dependent exponent $(0<s<1)$. The exponent " $s$ " characterizes the degree of interactions between charge carriers and their environment. The second term of eq. (11) $\left(A \omega^{s}\right)$ describes the frequency dependence of ac conductivity and characterizes all dispersion phenomena; besides "s " gives information about charge transport. At low frequencies, the temperature dependence of dc conductivity is given by:

$$
\sigma_{\mathrm{dc}}(T)=\sigma_{0} \exp \left(-E_{a} / K_{B} T\right)
$$

Where $\sigma_{0}$ is a pre-exponential factor which includes the charge carrier mobility and density of states, $E_{a}$ is the activation energy associated with dc conductivity, $K_{B}$ is Boltzmann constant and $\mathrm{T}$ is the absolute temperature.

Fig. 12 displays the Arrhenius plots of the dc conductivity (eq.(12)), which the slopes permit the evaluation of the activation energy for the all $\mathrm{TiO}_{2}$ samples. So, The activation energy was found to increase from $0.37 \mathrm{eV}$ for undoped sample to $1.07 \mathrm{eV}$ for $3 \% \mathrm{Zn}$-doped $\mathrm{TiO}_{2}$, as seen in Fig. 11(e), in accordance with the decrease of the dc conductivity. This can be explained by a reduction in the charge carriers mobility in doped $\mathrm{TiO}_{2}$. due to creation of deep level defects induced by the insertion of $\mathrm{Zn}$ in $\mathrm{TiO}_{2}$ structure. It is reported that the major defects that arise 
in $\mathrm{TiO}_{2}$ are titanium interstitials $\left(\mathrm{Ti}_{\mathrm{i}}\right)$ and oxygen vacancies $\left(\mathrm{V}_{\mathrm{O}}\right)$ [63]. According to the literature [64], oxygen vacancies form two energy levels at $0.75 \mathrm{eV}$ and $1.18 \mathrm{eV}$ below the conduction band, corresponding, respectively, to singly and doubly ionized oxygen vacancies $\left(\mathrm{V}_{0}\right)$. Correspondingly; the calculated activation energy of 0.37 $\mathrm{eV}$, for the undoped $\mathrm{TiO}_{2}$ sample, nearly matches that of the first ionization energy of oxygen vacancies $\left(\mathrm{V}_{\mathrm{O}^{-}}\right)^{-}$. While in $\mathrm{Zn}$-doped $\mathrm{TiO}_{2}$ the $\mathrm{E}_{\mathrm{a}}$ values were in accordance with the doubly ionized oxygen vacancies $\left(\mathrm{V}_{\mathrm{O}}{ }^{=}\right)$. So, as previously mentioned, the obtained $\mathrm{E}_{\mathrm{a}}$ values of the undoped and $\mathrm{Zn}$-doped samples can be attributed to singly and doubly ionized oxygen vacancies $\left(\mathrm{V}_{\mathrm{O}}\right)$ respectively. Thus, for doped $\mathrm{TiO}_{2}$, the increase of the activation energy originated from $\mathrm{Zn}^{2+}$ state charges incorporated into $\mathrm{TiO}_{2}$ matrix. Indeed, Zinc atoms act as donors by supplying two free electrons, when the $\mathrm{Zn}^{2+}$ ions occupy $\mathrm{Ti}^{4+}$ ion site.

Generally, the variation of the exponent "s" (eq. 11) is related to the conduction mechanism. This exponent "s" was calculated from the linear parts of $(\sigma=\mathrm{f}(f))$ at high frequencies (Fig. 12). The decrease of "s" with temperature

(Fig. 13) suggests that the correlated barrier hopping (CBH) mechanism governs the ac conduction [65-67]. This reflects the hopping of charge carriers between two sites over a barrier separating them.

\section{Photocatalytic tests}

The photocatalytic activities of undoped and $\mathrm{Zn}$ doped $\mathrm{TiO}_{2}$ were evaluated using the degradation of the standard organic $\mathrm{RhB}$ dye, under $\mathrm{UV}$ irradiation. For that the absorption of $\mathrm{RhB}$ dye solution with $\mathrm{TiO}_{2} \mathrm{NPs}_{\text {was }}$ measured and typical absorption spectra are plotted over the time in Fig. 14 (a). It is obvious that $\mathrm{TiO}_{2} \mathrm{NPs}_{\text {react }}$ well leading to a decrease of the main absorption band of RhB solution over the time. Indeed, $\mathrm{RhB}$ is a phenothiazine dye in which the chromophore part contains amino and thiocarbonyl bonds and exhibits a strong absorbance in the visible region $(554 \mathrm{~nm})$. However, the vanishing of this band reveals that the dye is degraded. Also, the photocatalytic activity exhibits a monotonous improvement by increasing $\mathrm{Zn}$ content and reaches the highest efficiency with $3 \%$ $\mathrm{Zn}$ doping even after 40min in dark (Fig. 14 (b)). Moreover, Fig. 14 (c) clearly shows that all $\mathrm{TiO}_{2}$ samples have high photocatalytic performances against RhB after 140min under UV irradiation, which was clearly improved by $3 \% \mathrm{Zn}$-doping. In fact, for this sample the photodegradation efficiency reached $95 \%$ while it was of $82 \%$ for the undoped $\mathrm{TiO}_{2}$. This fact may be related to the small average crystallite size (table 1) and a large specific area (fig.2) of the 3\% Zn-doped sample. The latest can help diffusion of the reactive molecules to the active sites, as the samples have porous morphology, which leads to an increase in the charge of the dye molecules and thus activates dye photodegradation.

Furthermore, from Fig. 14(b), one can notice a difference in photodegradation kinetics of RhB using undoped and $\mathrm{Zn}$ doped $\mathrm{TiO}_{2}$ nanopowders. Indeed, the kinetic rate is an important parameter in photodegradation studies because it can calculate the rate at which pollutant is removed from the aqueous solution. So, it is reasonable to quantify the photodegradation kinetics of the $\mathrm{RhB}$ dye. In all cases, the degradation kinetics are well adjusted to pseudo-first order process, which can be evaluated using Langmuir and Hishelwood formula [68]:

$$
\operatorname{Ln}\left(\mathrm{C}_{0} / \mathrm{C}\right)=\mathrm{K}_{\text {app. }} \text {. }
$$

where $\mathrm{K}_{\text {app }}$ is the apparent rate constant of the first-order reaction $\left(\mathrm{min}^{-1}\right)$.

A plot of (Eq. (13)) is given in Fig. 14(d). It exhibits a straight line which the slope equals the apparent first-order rate constant $\mathrm{K}_{\text {app }}$. The obtained values are plotted versus $\mathrm{Zn}$ doping content, and presented in the insert of Fig. 14(d). As shown, the $3 \% \mathrm{Zn}$ doped $\mathrm{TiO}_{2}$ sample has the higher rate constant, so, it degrades the $\mathrm{RhB}$ dye faster. This proves the enhancement of photocatalytic performance of $\mathrm{TiO}_{2}$ by $\mathrm{Zn}$ doping.

\section{Conclusion}


In summary, undoped and $\mathrm{Zn}$ doped $\mathrm{TiO}_{2}$ has been successfully prepared by sol-gel method. All synthesized nanopowders are formed by a mixture of rutile and anatase crystalline phases with tetragonal structure. Zn doping highly modified the powder morphology and leads to the formation of nanosheets. The specific surface area increased with the increase of doping concentration. The optical band gap decreases with the increase of $\mathrm{Zn}$ content, due to defects creation and the decrease of the average crystallite size. Dielectric properties were analyzed using complex impedance for the sample at various temperatures. The impedance plots are well fitted to an $\left(\mathrm{R}_{1} / / \mathrm{C}_{1}\right)-\left(\mathrm{R}_{2} / / \mathrm{CPE}_{1}\right)$ equivalent electrical circuit. The equivalent circuit parameters estimated from theoretical fit proved the enhancement of capacitive behavior of the $\mathrm{Zn}$ doped $\mathrm{TiO}_{2}$. The frequency dependence of the conductivity is interpreted in term of Jonschers law. As well, the conduction mechanism was dominated by the correlated barrier hopping model $(\mathrm{CBH})$. Finally, Photocatalytic activities of the $\mathrm{Zn}$ doped $\mathrm{TiO}_{2}$ nanoparticles were evaluated via the degradation of $\mathrm{RhB}$ dye aqueous solution under UV light irradiation. Also, the results showed that $\mathrm{Zn}$ doped $\mathrm{TiO}_{2}$ nanopowders exhibit a noticeably improvement of photodegradation of RhB dye typically for $3 \% \mathrm{~mol} \mathrm{Zn}$ doping, compared to the undoped $\mathrm{TiO}_{2}$ nanoparticles. Its photodegradation efficiency reaches $95 \%$ after irradiation time of $140 \mathrm{~min}$. The kinetic study revealed that $3 \% \mathrm{~mol} \mathrm{Zn}$ doped $\mathrm{TiO}_{2}$ sample is promising photocatalyst for the degradation of $\mathrm{RhB}$ pollutant. Further works are planned to test these samples in other sensitivity applications such as gas and bio-sensors. 


\section{References}

[1] N.S.P. Bhuvanesh, J. Gopalkrishnan, J. Mater. Chem. 7, 2297(1997)

[2] T. Fuyuki, H. Matsunami, Jpn. J. Appl. Phys. 25, 1288 (1986)

[3] C. Guo, M. Ge, L. Liu, G. Gao, Y. Feng, Y. Wang, Environ. Sci. Technol. 44, 419 (2009)

[4] X. Li, J. He, ACS Appl. Mater. Interfaces 5, 5282 (2013)

[5] Z. Wang, X. Peng ,C. Huang, X.Chen ,W. Dai,X.Fu, Appl. Catal. B. 219, 379 (2017)

[6] J. Reszczyn`ska, T. Grzyb, J.W. Sobczak, W. Lisowski, M. Gazda, B. Ohtani, A. Zaleska, Appl. Surf. Sci. 307333 (2014)

[7] J. Ben Naceur, M. Gaidi, F. Bousbih, R. Mechiakh, R. Chtourou, Curr. Appl. Phys. 12, 422 (2012)

[8] Y. Shang-Wei, K. Horng-Huey, C. Hsiu-Mei, C. Yen-Ling, L. Jian-Hong, W. Chiu-Ming, W.Moo-Chin, J. Alloys Compd. 613, 107 (2014)

[9] R. Bargougui, N. Bouazizi, W. Ben Soltan, A. Gadri, A. Azzouz, S. Ammar, Appl. Phys. A 122, (2016), https://doi.org/10.1007/s00339-016-9837-9

[10] H.P. Chang, F.H. Wang, J.C. hao, C.C. Huang, H.Liu, Appl. Phys. 11, 185 (2011).

[11] Q. Zhang, C. Li, Catalysis Today 19, 1 (2019)

[12] S.N. Mazhir, G.H. Mohamed, A.A. Abdullah, M.D. Radhi, Int. J. Adv. Res. 3, 1060 (2015)

[13] I. Dundar, M. Krichevskaya, A. Katerski, I.O. Acik, R. Soc. Open Sci, 6, 181578 (2019)

[14] X. Pan, M. Q-Yang, X. Fu , N. Zhang, Y.J. Xu, ,NLM 5, 3601 (2013)

[15] K. M. Pangan-Okimoto, P. Gorai, A. G. Hollister, E.G. Seebauer, J. Phys. Chem. 119, 9955 (2015)

[16] Z-Y. Shen, Q-G. Hu, Y-M. Li, Z-M. Wang, W-Q. Luo,R-H. Liao, J. Mat. Sci. Mat. Elec 24, 3089 (2013)

[17] B. Santara, PK. Giri, K. Imakita, M. Fujii, J. Phys. Chem. 117, 23402 (2013)

[18] Y. Shi , H. Sun , MC. Nguyen , C. Wang , K.Ho, WA.Saidi , J.Zhao, NLM 9, 11553 (2017)

[19] W. Tuichai, S. Danwittayakul, N. Chanlek, P. Thongbai, J. Alloys. Compd, 725, 310 (2017)

[20] H. Peng, B. Shang, X. Wang, Z. Peng, X. Chao, P. Liang, Z.Yang., Ceram. Int. 44, 5768 (2018)

[21] X. Zhao, P. Liu, J. Alloys Compd. 715, 170 (2017)

[22] N. Al Saqri, A. Mondal, J. F. Felix, Y. G. Gobato, V. O. Gordo, H. Albalawi, D. Jameel, H. Alghamdi, F. Al Mashary, D. Taylor, M. S.Abd El-sadek, M. Henini, J. Alloys Compd. 698, 883 (2017)

[23] Q.Cai,Y.Zhang, C. Liang, P. Li, H. Gu , X. Liu, J. Wang, Z. Shentu, J. Fan, G. Shao, Electrochim. Acta. 261, 227 (2018)

[24] K. Elghniji, A. Atyaoui, S. Livraghi, L. Bousselmi, E. Giamello, M. Ksibi, J. Alloys. Compd,541, 421 (2012)

[25] I. Elmehasseb, S. Kandil, K. Elgendy, Optik 213, (2020), https://doi.org/10.1016/j.ijleo.2020.164654

[26] C. Wattanawikkam, W. Pecharapa, Radiation Physics and Chemistry 171, (2020), https://doi.org/10.1016/j.radphyschem.2020.108714

[27] H.M. Rietveld, J. Appl. Crystallogr. 2, 65 (1969)

[28] E. Barsoukov, J.R. Macdonald, 2nd edn (Wiley, Hoboken, 2005), pp 1-20

[29] H. Bel Hadjltaief, S. Ben Ameur, P. Da Costa, M. Ben Zina, M.E. Galvez, Appl. Clay Sci. 152, 148 (2018)

[30] S. Ben Ameur, H. Bel hadjltaief, A. Barhoumi, B. Duponchel, G. Leroy, M. Amlouk, H. Guermazi, Vacuum $155,546(2018)$

[31] S. Ben Ameur, A. Barhoumi, H. Belhadjltaief, R. Mimouni, B. Duponchel, G. Leroy, M. Amlouk, H. Guermazi, Mater. Sci. Semicond. Process. 61, 17 (2017) 
[32] S. Ben Ameur, H. BelHadjltaief, B. Duponchel, G. Leroy, M. Amlouk, H. Guermazi, S. Guermazi, Heliyon V5, Issue 6, e01912 (2019)

[33] A. Maurya, P. Chauhan, S.K. Mishra, R.K. Srivastava, J. Alloys Comp. 509, 8433 (2011)

[34] A. S-Martinez, O. C-Sanchez, C. K-Santa, C. E. R., E. L-Mena. O-Guareño,M. G-Guaderrama, Ceramics. Inter 44, 5273 (2018)

[35] V. R. Akshay, B. Arun, S. Dash, A. K. Patra, G. Mandal, G.R. Mutta, A. Chanda, M. Vasundhara, RSC. Adv 8,41994 (2018)

[36] Z. Zheng, B. Huang, , X. Meng, J. Wang, , S.Wang, , Z. Lou, , Y. Dai, Chem. Commun 49, 868 (2013)

[37] V. R. Akshay, B. Arun, S. Dash, A. K. Patra, G. Mandal, G. R. Mutta, A. Chanda, M. Vasundhara, R.S.C. Advances 8, 41994 (2018)

[38] R.B.Bylsma, M.Becker, J.Kossut, U.Debska., Phys. Rev. B 33, 8207 (1986)

[39] M. Ismael, New. J. Chem. 43, 9596 (2019)

[40] M. Bärtsch, M. Niederberger, Chem. Plus. Chem 82, 42 (2017)

[41] E.J. Abram, D.C. Sinclair, A.R. West, J Electroceram.10, 165 (2003)

[42] M. Chaari, A. Matoussi, Phys B. 407, 3441 (2012)

[43] N. Kılınc, S. Ozturk,L. Arda, A. Altındal, Z.Z. Ozturk, J Alloy Compd. 536, 138 (2012)

[44] J. Plocharski, W. Wieczoreck, Solid State Ionics 28, 979 (1988)

[45] D.C.Sinclair, A.R.West, J Mater Sci. 29, 6061 (1994)

[46] W. Dong, W.Hu, A Berlie ,. K. Lau, H. Chen, R. L. Withers, Y Liu, ACS Appl Mater. Inter 7, 25321 (2015)

[47] J.B. Jorcin, ME. Orazem, N. Pebere, B. Tribollet, Electrochim Acta 51:1473, 9 (2006)

[48] Y.V. Didenko, Y.M. Poplavko, IEEE XXXIV International Scientific Conference Electronics and Nanotechnology, 73 (2014)

[49] P. Pissis, A. Kyritsis, Solid. State. Ion 97, 105 (1997)

[50] M.H. Khan, S. Pal, E. Bose, Appl. Phys. A. 118, 907 (2015)

[51] V. Provenzano, LP. Boesch, V. Volterra, CT. Moynihan, PB. Macedo, J.Am.Ceram Soc.55, 492 (1972).

[52] M.H. Abdullah, A.N. Yusoff, J. Mat. Sci. 32, 5817 (1997)

[53] R. Ranjan, R. Kumar, N. Kumar, B. Behera, R. N. P. Choudhary, J Alloy Compd. 509, 6388 (2011)

[54] P.B.Macedo, C.T.Moynihan, R.Bose, Phys. Chem.Glasses13, 171 (1972)

[55] M. K. H. Bhuiyan1, M. A. Gafur, M. N. I. Khan, A. A. Momin, A. K. M. Akther Hossain, Ceramics Mat. Sc and Applications 8, 64 (2017)

[56] Y. Ben Taher, N. Moutia, A. Oueslati, M. Gargouri, RSC Adv. 6, 39750 (2016)

[57] M. Ashokkumar, S Muthukumaran, J. Lumin 162, 97 (2015)

[58] X. Li, X. Cao, L. Xu, L. Liu, Y. Wang, C. Meng, Z. Wang, Journal of Alloys and Compounds, 657, 90 (2016)

[59] Zhao-Jin Wu, Wei Huang, Ke-Ke Cui, Zhi-Fang Gao, Ping Wang, J. Hazard Mater 278, 91 (2014)

[60] X. Qiu, L. Li, J. Zheng, J. Liu, X. Sun, G. Li, J. Phys. Chem. C 112, 12242 (2008)

[61] Chi-Jung Chang, Tsung-LinYang, Yu-ChingWeng, J. Solid State Chem. 214, 101 (2014)

[62] C. Leon, A. Rivera, A. Varez, J. Sanz, J. Santamaria, K.L. Ngai, Phys. Rev. Lett. 86, 1279 (2001)

[63] N. Ait-Younes, F. Millot, P. Gerdanian,Solid State Ionics 12, 431 (1984)

[64] D. K. Lee and H. I. Yoo, Solid. State Ionics. 177, 1 (2006) 
[65] L. Essaleh, S. Amhil, S.M. Wasim, G. Marín, E. Choukri, L. Hajji, Physica E: Low-dimens. Syst. Nanostruct 99, 37 (2018)

[66] O. Ajili, B. Louati, K. Guidara, J. Mater. Sci. Mater. Electron. 29, 8649 (2018)

[67] J. Mohanty, P. Behera, S. R. Mishra, T. Badapanda, S.Anwar, IOP Conf. Ser.: Mater. Sci. Eng. 178, 012014 (2017)

[68] A. Turki, C. Guillard, F. Dappozze, Z. Ksibi, G. Berhault, and H. Kochkar; Appl. Catal. B-Approx, 163, 404 (2015) 


\section{Figure Captions}

Fig.1. X-ray diffractograms of undoped $\mathrm{TiO}_{2}$ (a), and $\mathrm{Zn}$ doped $\mathrm{TiO}_{2}$ with $1 \mathrm{~mol} \%$ (b) $2 \mathrm{~mol} \%$ (c) and 3 mol\% (d)

Fig.2. specific surface area of $\mathrm{TiO}_{2}$ nanopowder as a function of $\mathrm{Zn}$ content

Fig.3 The SEM images of (a) undoped and (b) 1 mol\% $\mathrm{Zn}$ doped $\mathrm{TiO}_{2}$. (c) average grain size of the undoped $\mathrm{TiO}_{2}$ powder

Fig.4. FT-IR spectra of undoped $\mathrm{TiO}_{2}$ (a), and $\mathrm{Zn}$ doped $\mathrm{TiO}_{2}$ with $1 \mathrm{~mol} \%$ (b), $2 \mathrm{~mol} \%$ (c) and $3 \mathrm{~mol} \%$ (d)

Fig.5. (a) Absorption spectra of undoped and $\mathrm{Zn}$ doped $\mathrm{TiO}_{2}$ samples, and (b) the corresponding Tauc's plots

Fig.6. Nyquist diagrams of (a) undoped, (b) $\mathrm{Zn} 1 \%$ doped $\mathrm{TiO}_{2}$, (c) $\mathrm{Zn} 2 \%$ doped $\mathrm{TiO}_{2}$ and (d) $\mathrm{Zn} 3 \%$ doped $\mathrm{TiO}_{2}$ as a function of temperature

Fig.7. Frequency-temperature dependence of Z' of (a) undoped, (b) $\mathrm{Zn} 1 \%$ doped $\mathrm{TiO}_{2}$, (c) $\mathrm{Zn}_{2} \%$ doped $\mathrm{TiO}_{2}$ and (d) $\mathrm{Zn} 3 \%$ doped $\mathrm{TiO}_{2}$

Fig.8. Frequency-temperature dependence of $\mathrm{Z}^{\prime \prime}$ of (a) undoped, (b) $\mathrm{Zn} 1 \%$ doped $\mathrm{TiO}_{2}$, (c) $\mathrm{Zn}_{2} \%$ doped $\mathrm{TiO}_{2}$ and (d) $3 \% \mathrm{Zn}$ doped $\mathrm{TiO}_{2}$

Fig.9. Frequency dependence of the imaginary part of dielectric permittivity of (a) undoped, (b) $1 \% \mathrm{Zn}$ doped $\mathrm{TiO}_{2}$, (c) $2 \% \mathrm{Zn}$ doped $\mathrm{TiO}_{2}$ and (d) $3 \% \mathrm{Zn}$ doped $\mathrm{TiO}_{2}$

Fig.10. Frequency dependence of the imaginary part M" of the electric modulus for: (a) undoped, (b) Zn1\% doped $\mathrm{TiO}_{2}$, (c) $2 \% \mathrm{Zn}$ doped $\mathrm{TiO}_{2}$ and (d) $3 \% \mathrm{Zn}$ doped $\mathrm{TiO}_{2}$, as a function of temperature

Fig.11. Frequency dependence of the AC conductivity for (a) undoped, (b) $\mathrm{Zn} 1 \%$ doped $\mathrm{TiO}_{2}$, (c) $\mathrm{Zn} 2 \%$ doped $\mathrm{TiO}_{2}$ and (d) $\mathrm{Zn} 3 \%$ doped $\mathrm{TiO}_{2}$, as a function of temperature, and (e) the dc conductivity at $480 \mathrm{~K}$, as well as its activation energy vs $\mathrm{Zn}$ doping

Fig.12. The evolution of $\left(\operatorname{Ln}\left(\sigma_{\mathrm{dc}} \mathrm{T}\right)\right)$ versus reciprocal temperature for (a) undoped, (b) $1 \% \mathrm{Zn}$ doped $\mathrm{TiO}_{2}$, (c) $2 \% \mathrm{Zn}$ doped $\mathrm{TiO}_{2}$ and (d) $3 \% \mathrm{Zn}$ doped $\mathrm{TiO}_{2}$

Fig.13. Variation of $\mathbf{s}$ as a function of temperature for (a) undoped, (b) $1 \% \mathrm{Zn}$ doped $\mathrm{TiO}_{2}$, (c) $2 \% \mathrm{Zn}$ doped $\mathrm{TiO}_{2}$ and (d) $3 \% \mathrm{Zn}$ doped $\mathrm{TiO}_{2}$

Fig.14.The variation as a function of the irradiation time of (a) absorbance of RhB solution with $\mathrm{TiO}_{2}$ nanopowder (b) $\mathrm{C} / \mathrm{C}_{0}$ ratio, (c) photodegradation efficiency after 140 mins under $\mathrm{UV}$ irradiation, $(\mathrm{d}) \mathrm{Ln}\left(\mathrm{C}_{0} / \mathrm{C}\right)$ 


\section{Table Captions}

Table 1. Structural parameters of the Anatase and Rutile phases

Table 2. Equivalent circuit parameters of the undoped $\mathrm{TiO}_{2}$ sample

Table 3. Equivalent circuit parameters of the $1 \mathrm{~mol} \% \mathrm{Zn}-\mathrm{TiO}_{2}$ sample

Table 4. Equivalent circuit parameters of the $2 \mathrm{~mol} \% \mathrm{Zn}$ doped $\mathrm{TiO}_{2}$ sample

Table 5. Equivalent circuits parameters of the $3 \mathrm{~mol} \% \mathrm{Zn}$ doped $\mathrm{TiO}_{2}$ sample

Table 6. The apparent kinetic rate constants of all $\mathrm{TiO}_{2}$ samples 
Figures

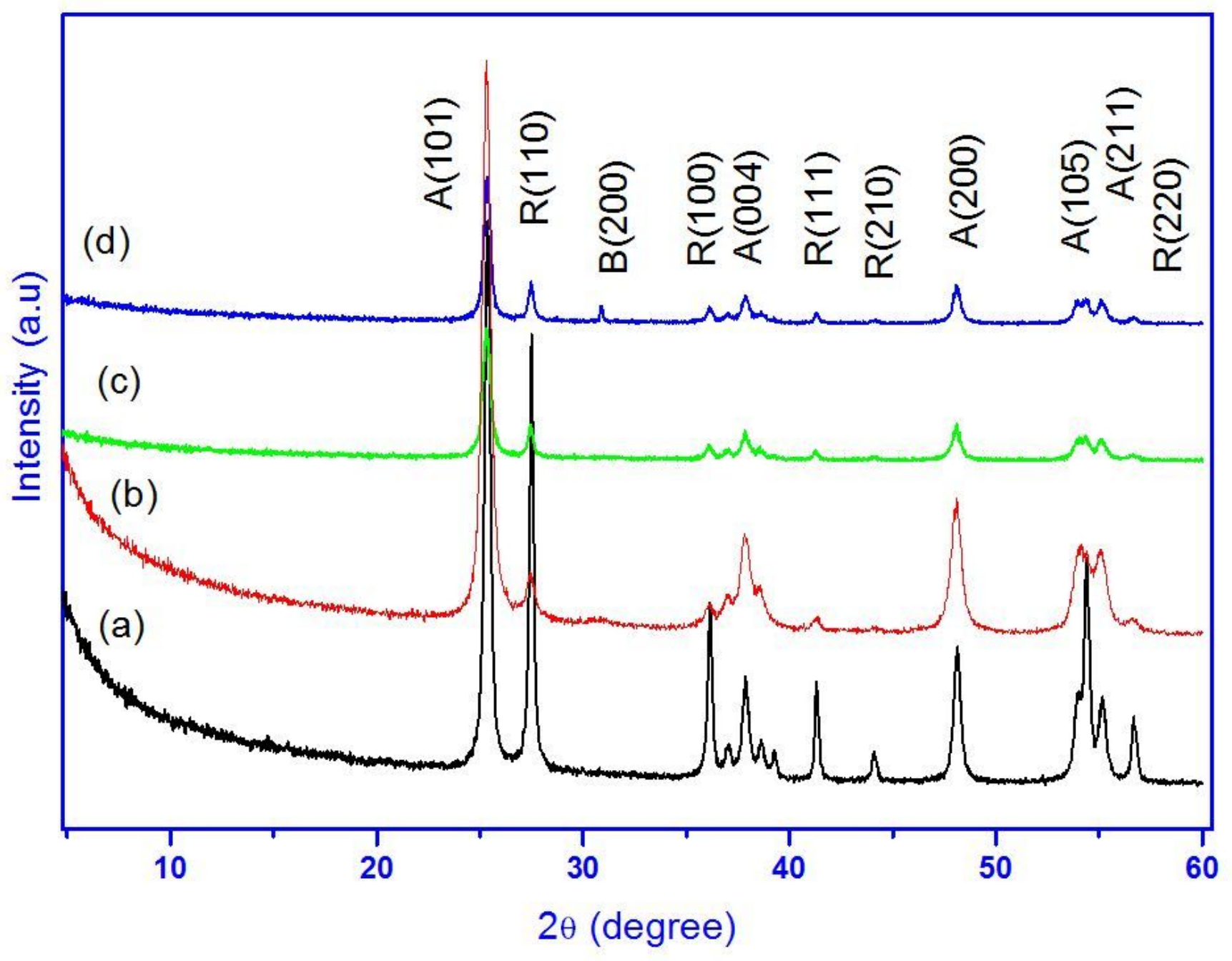

Figure 1

X-ray diffractograms of undoped TiO2 (a), and Zn doped TiO2 with $1 \mathrm{~mol} \%$ (b) $2 \mathrm{~mol} \%$ (c) and $3 \mathrm{~mol} \%$ (d) 


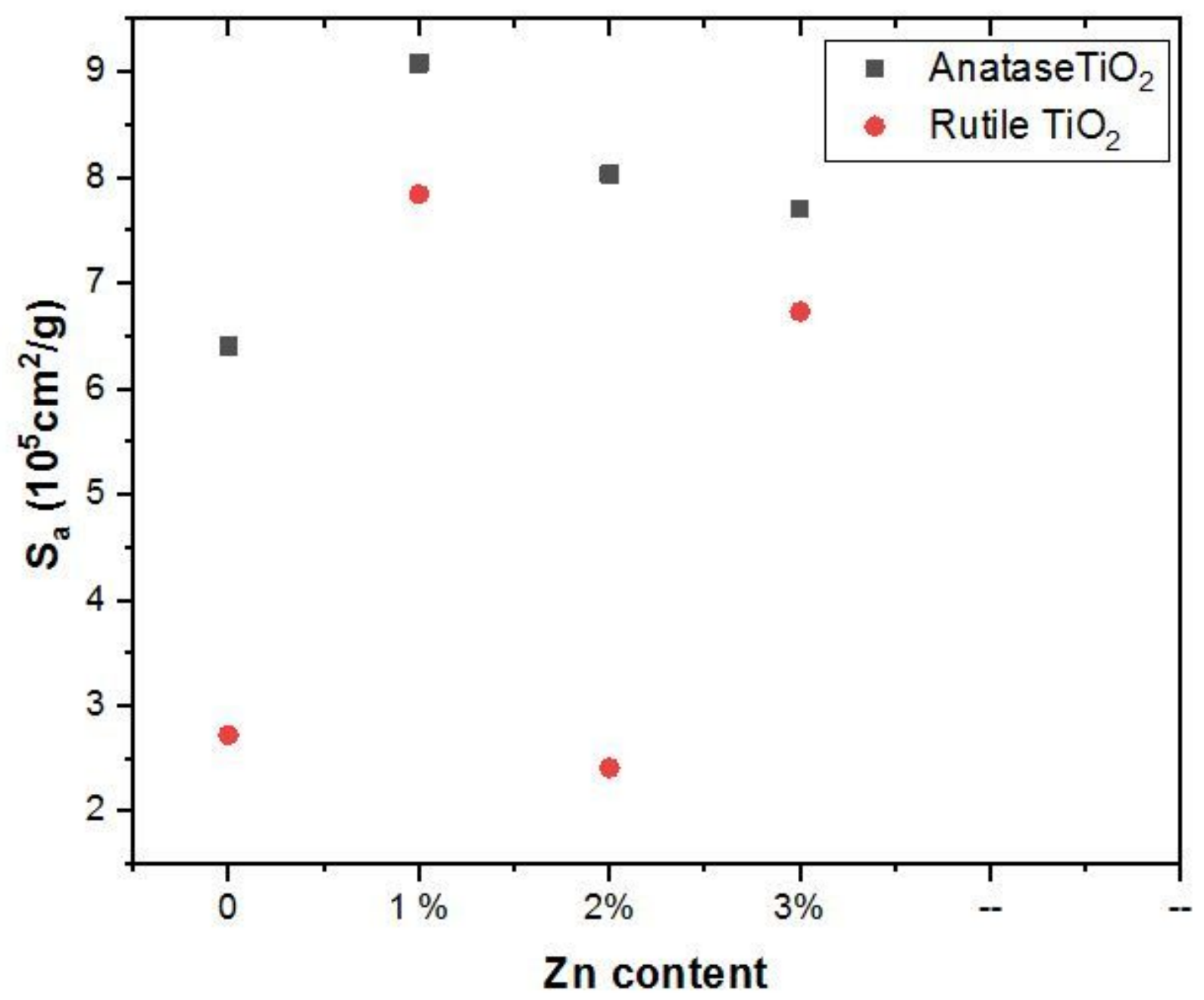

Figure 2

specific surface area of $\mathrm{TiO} 2$ nanopowder as a function of $\mathrm{Zn}$ content 

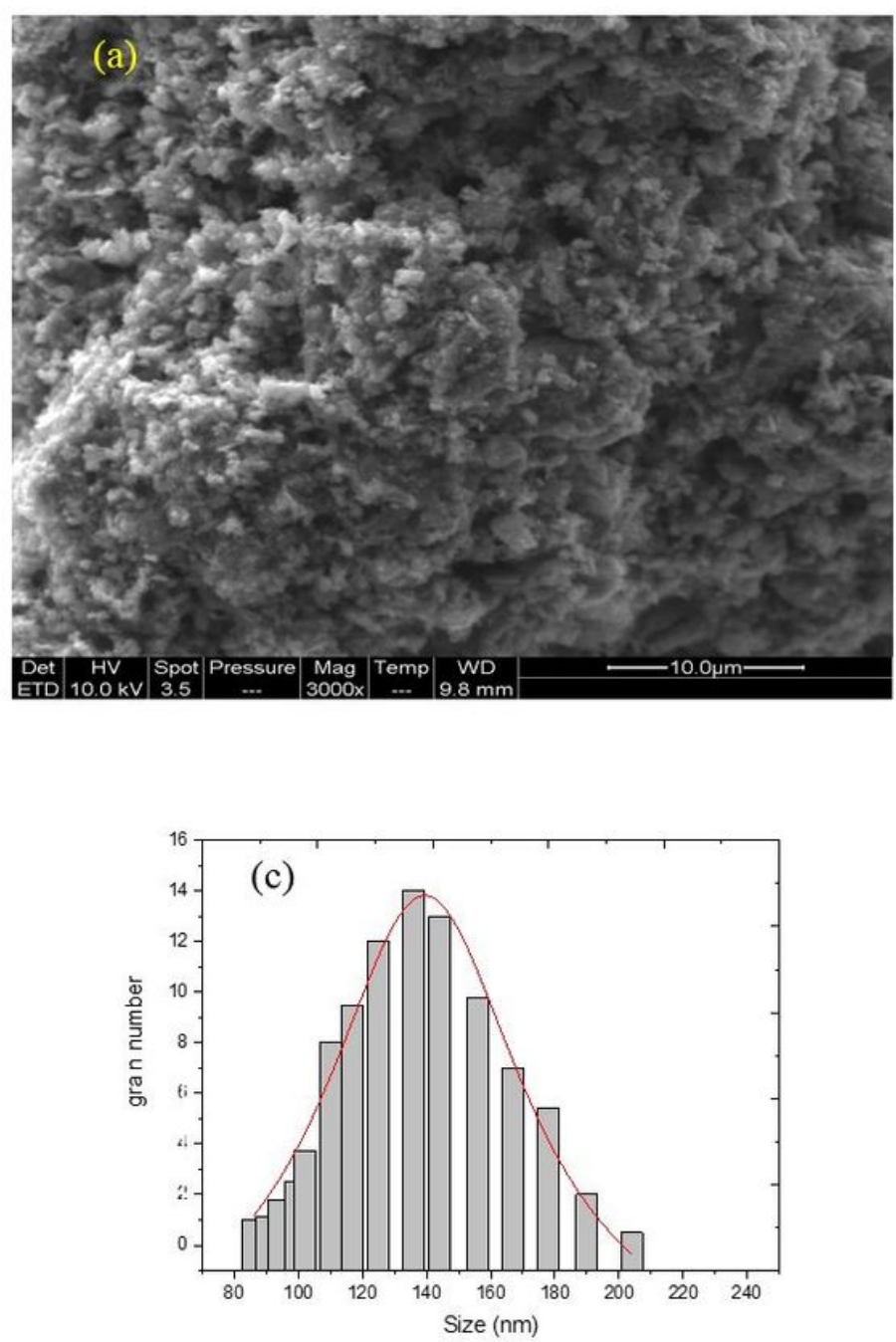

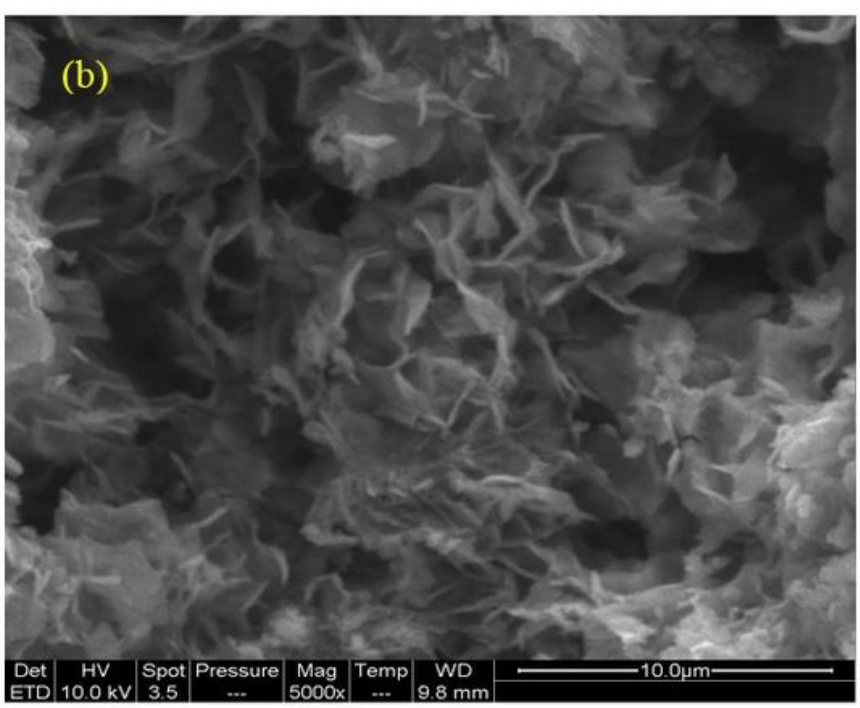

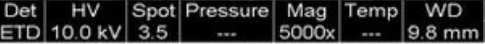

\section{Figure 3}

The SEM images of (a) undoped and (b) $1 \mathrm{~mol} \% \mathrm{Zn}$ doped TiO2. (c) average grain size of the undoped TiO2 powder 


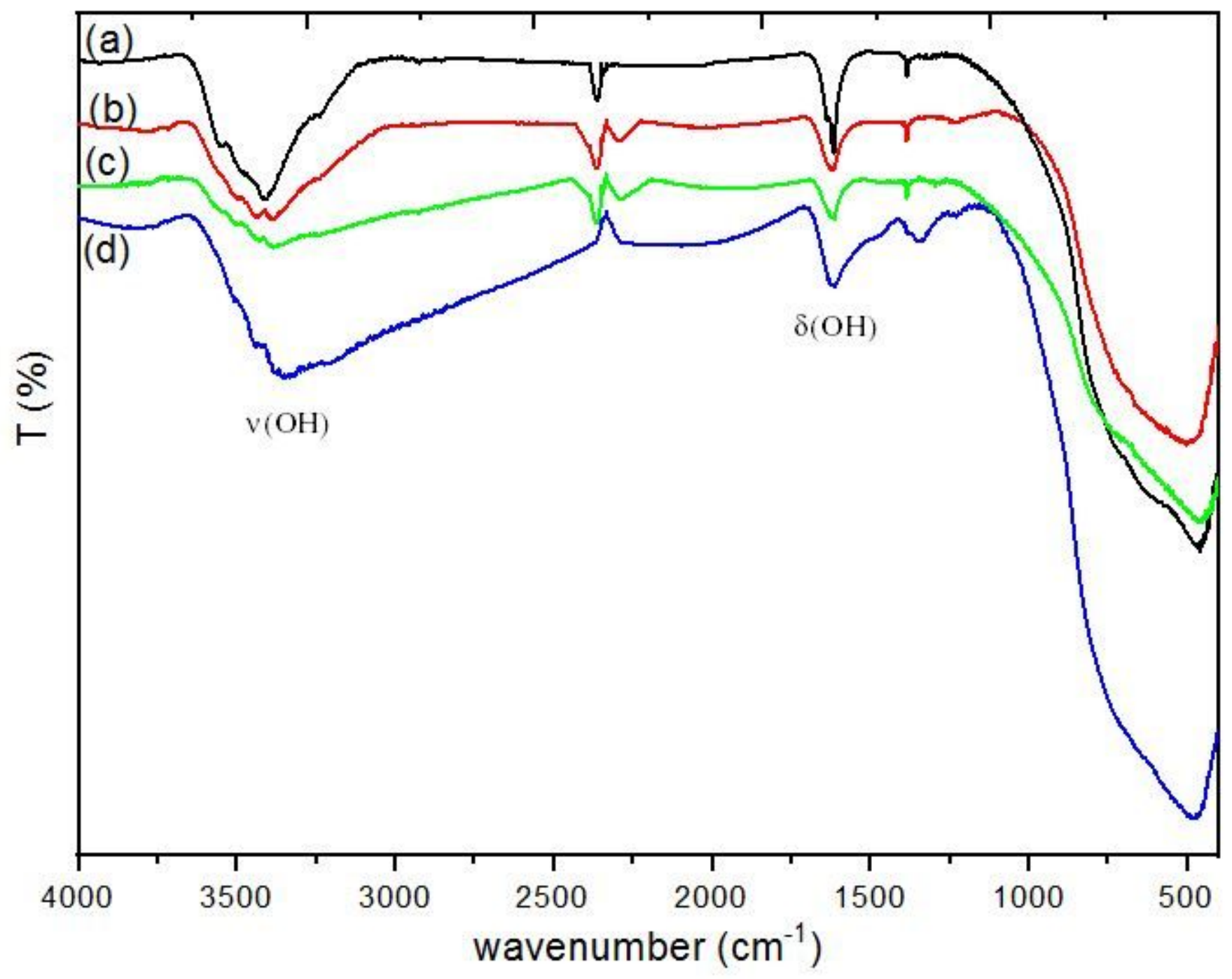

Figure 4

FT-IR spectra of undoped TiO2 (a), and Zn doped TiO2 with 1 mol\% (b), 2 mol\% (c) and 3 mol\% (d) 

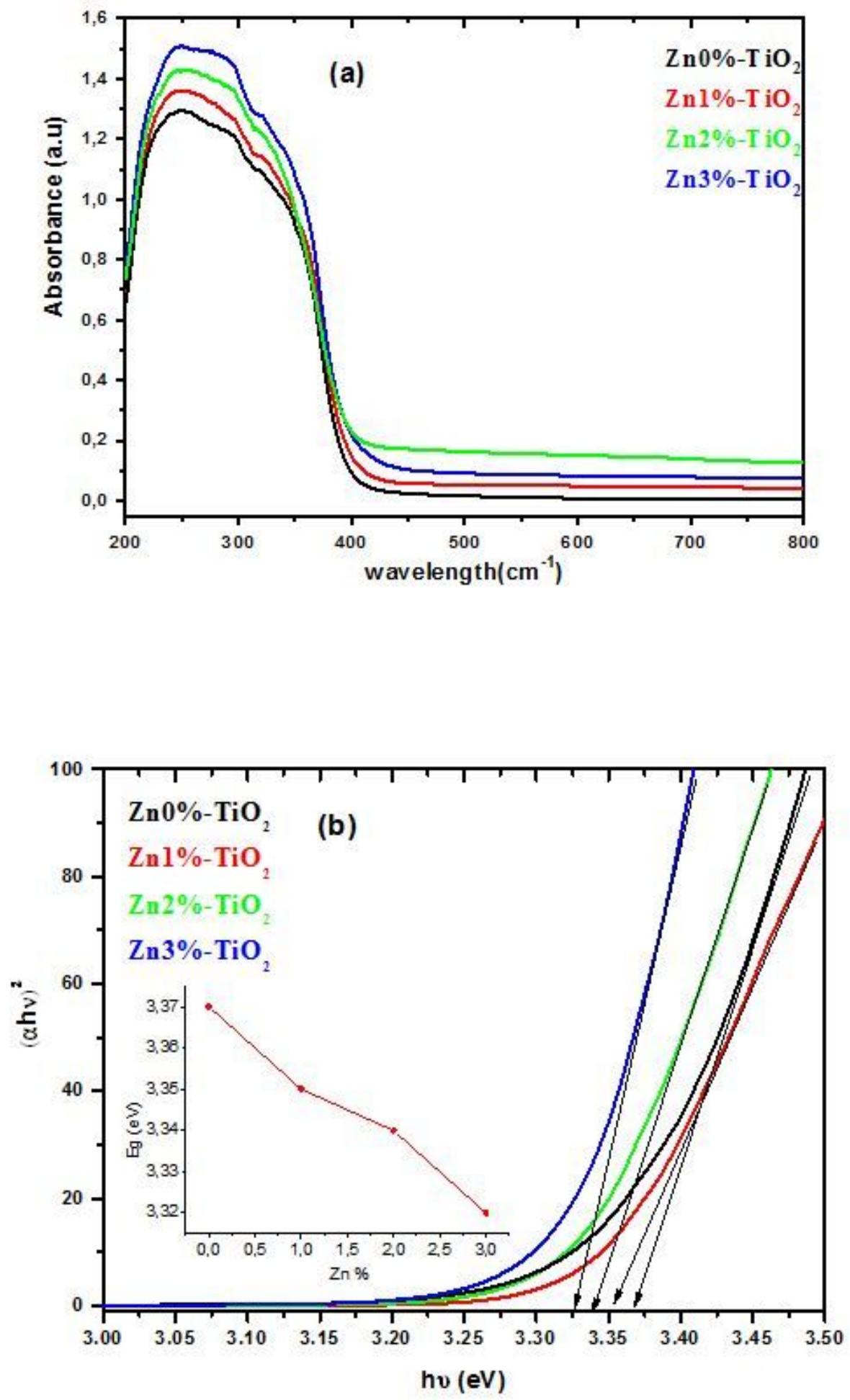

Figure 5

(a) Absorption spectra of undoped and Zn doped TiO2 samples, and (b) the corresponding Tauc's plots 

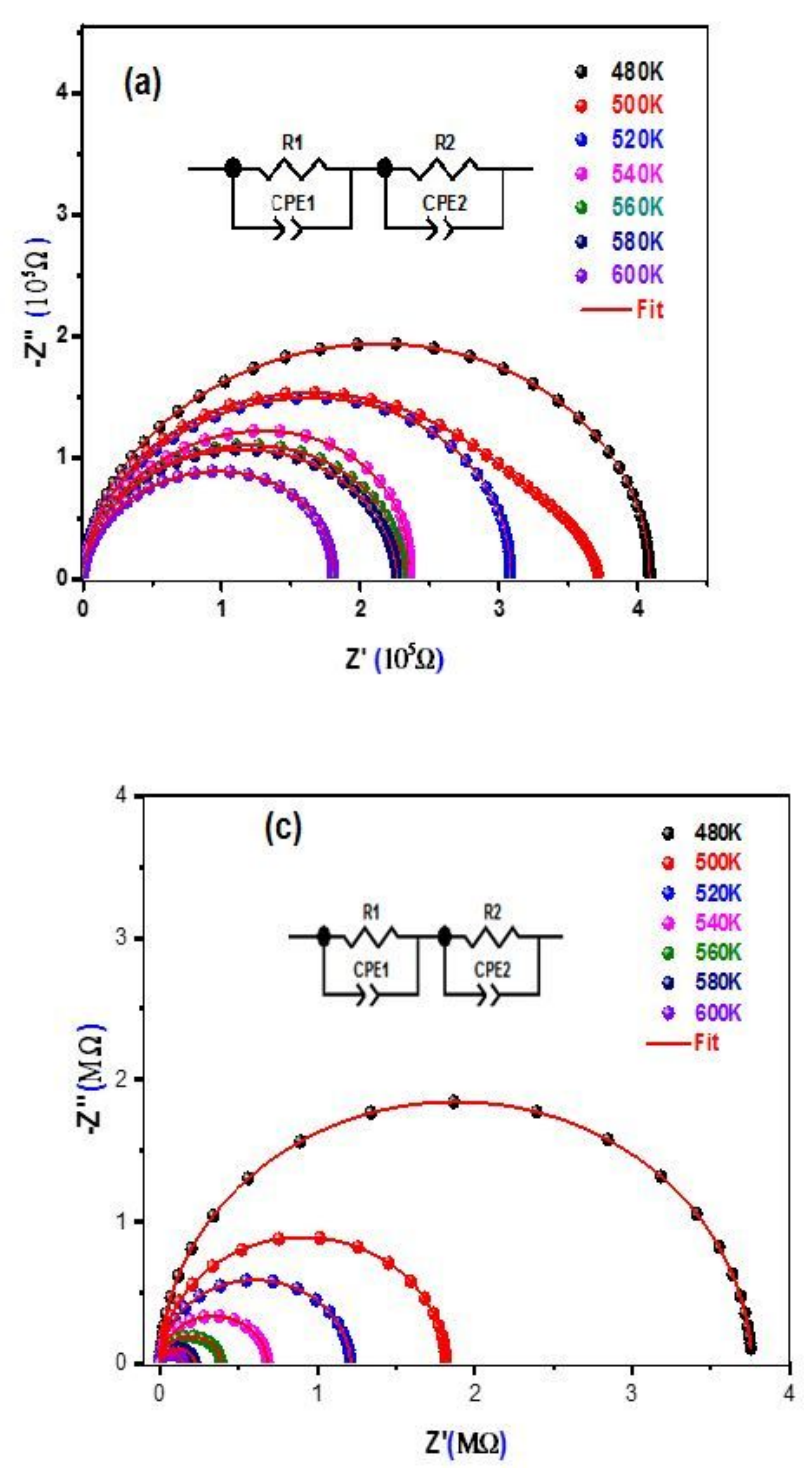
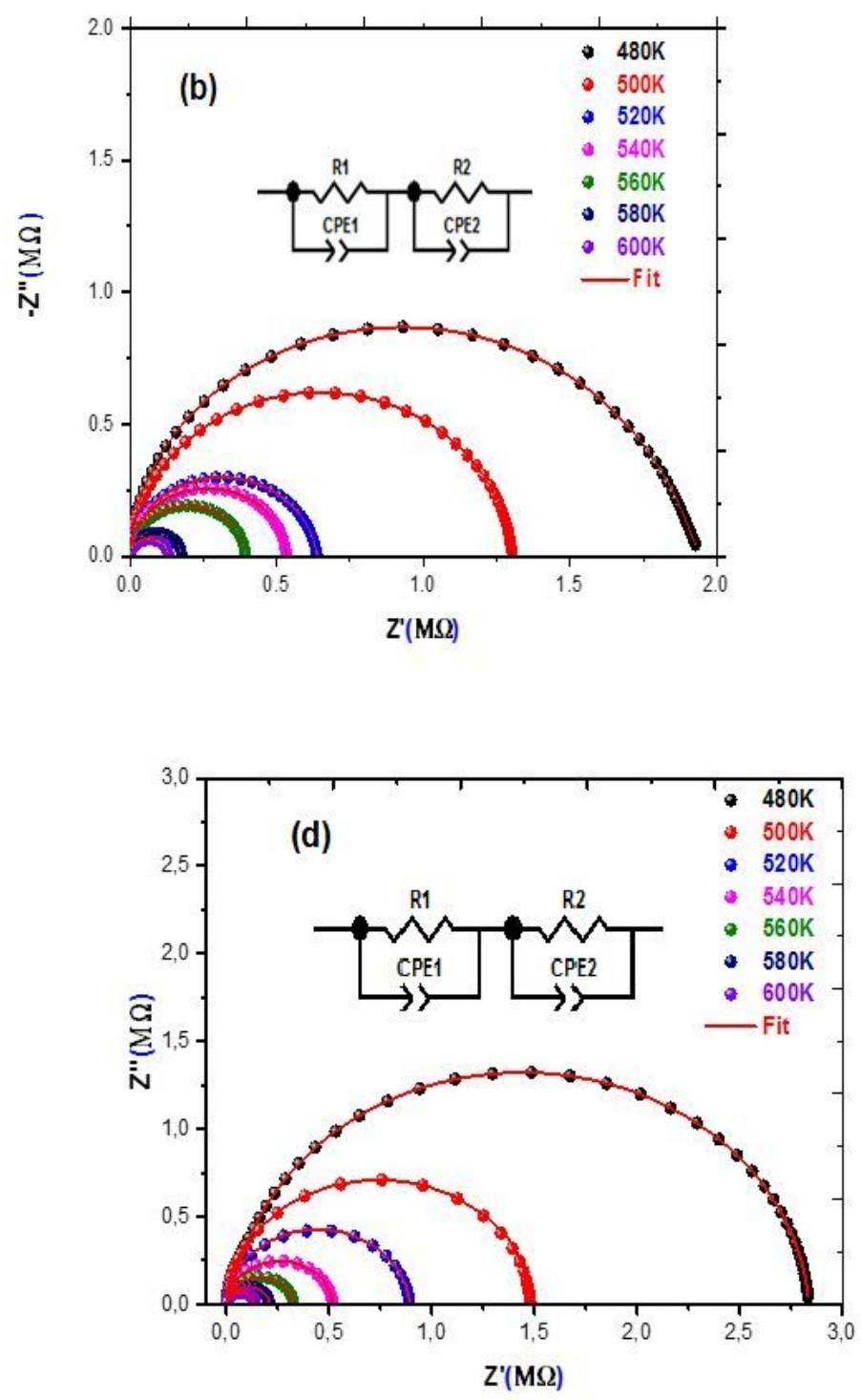

Figure 6

Nyquist diagrams of (a) undoped, (b) Zn1\% doped TiO2, (c) Zn2\% doped TiO2 and (d) Zn3\% doped TiO2 as a function of temperature 

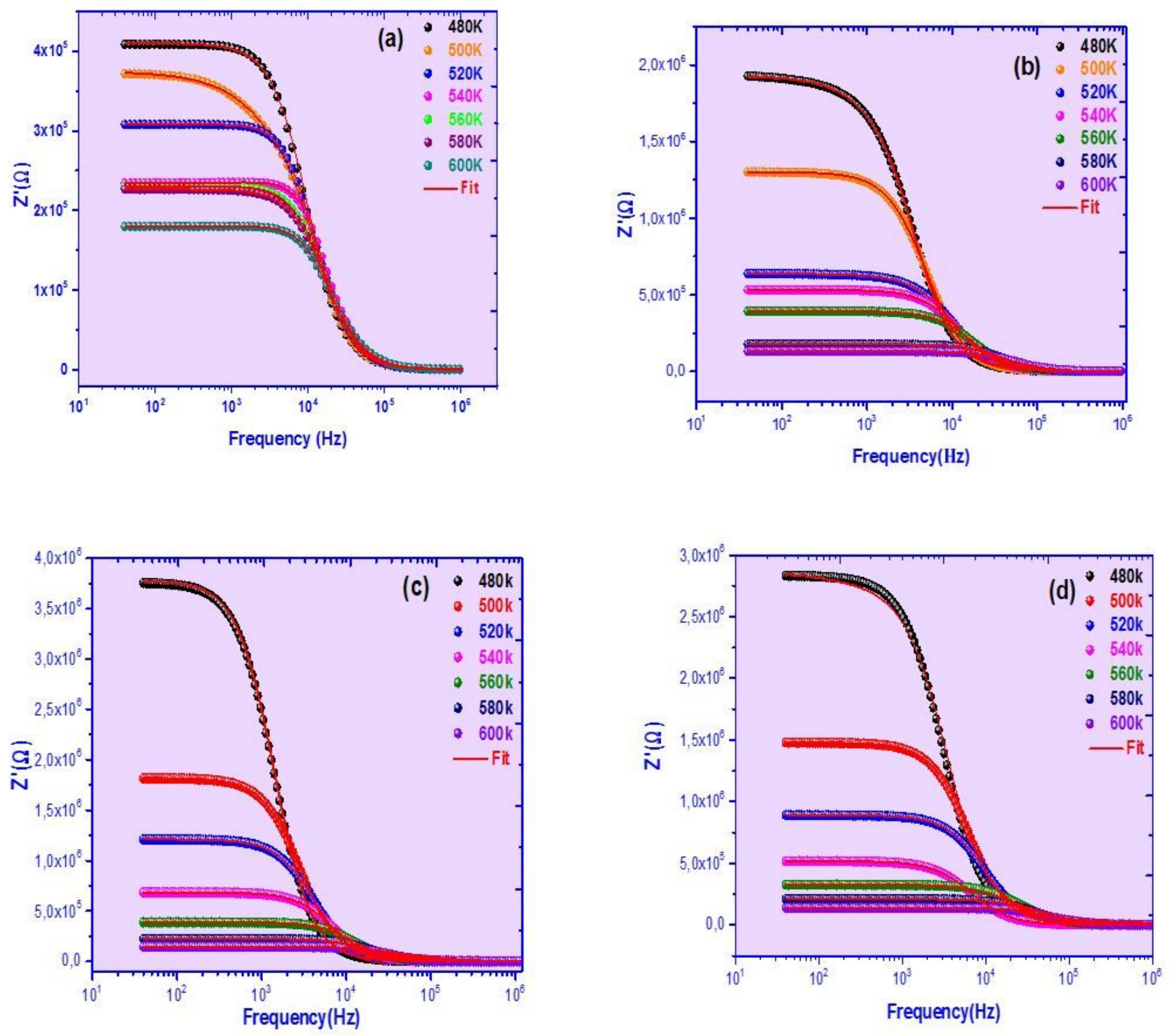

Figure 7

Frequency-temperature dependence of Z' of (a) undoped, (b) Zn1\% doped TiO2, (c) Zn2\% doped TiO2 and (d) $\mathrm{Zn3} \%$ doped $\mathrm{TiO} 2$ 

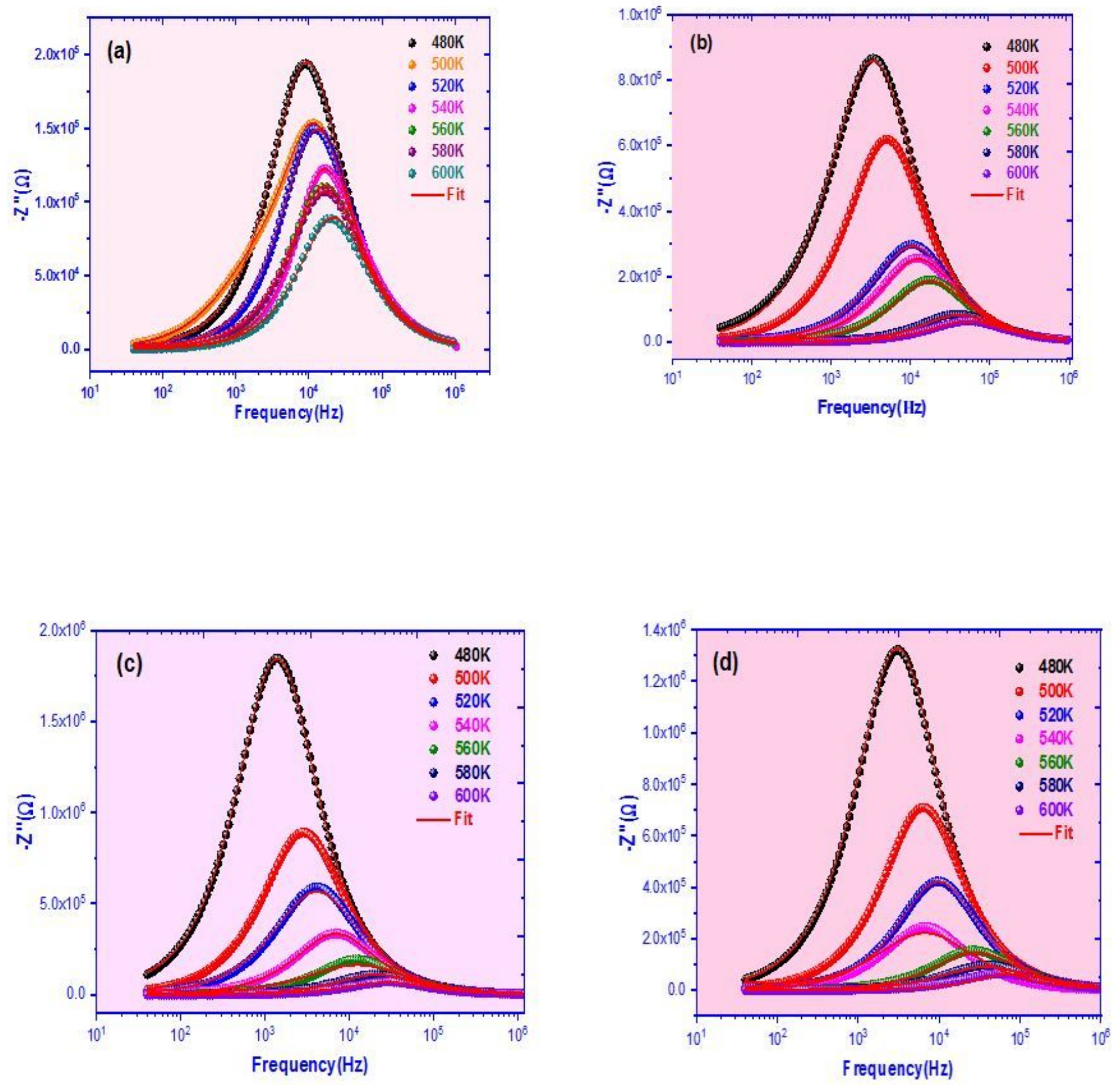

Figure 8

Frequency-temperature dependence of Z" of (a) undoped, (b) Zn1\% doped TiO2, (c) Zn2\% doped TiO2 and (d) $3 \% \mathrm{Zn}$ doped $\mathrm{TiO} 2$ 

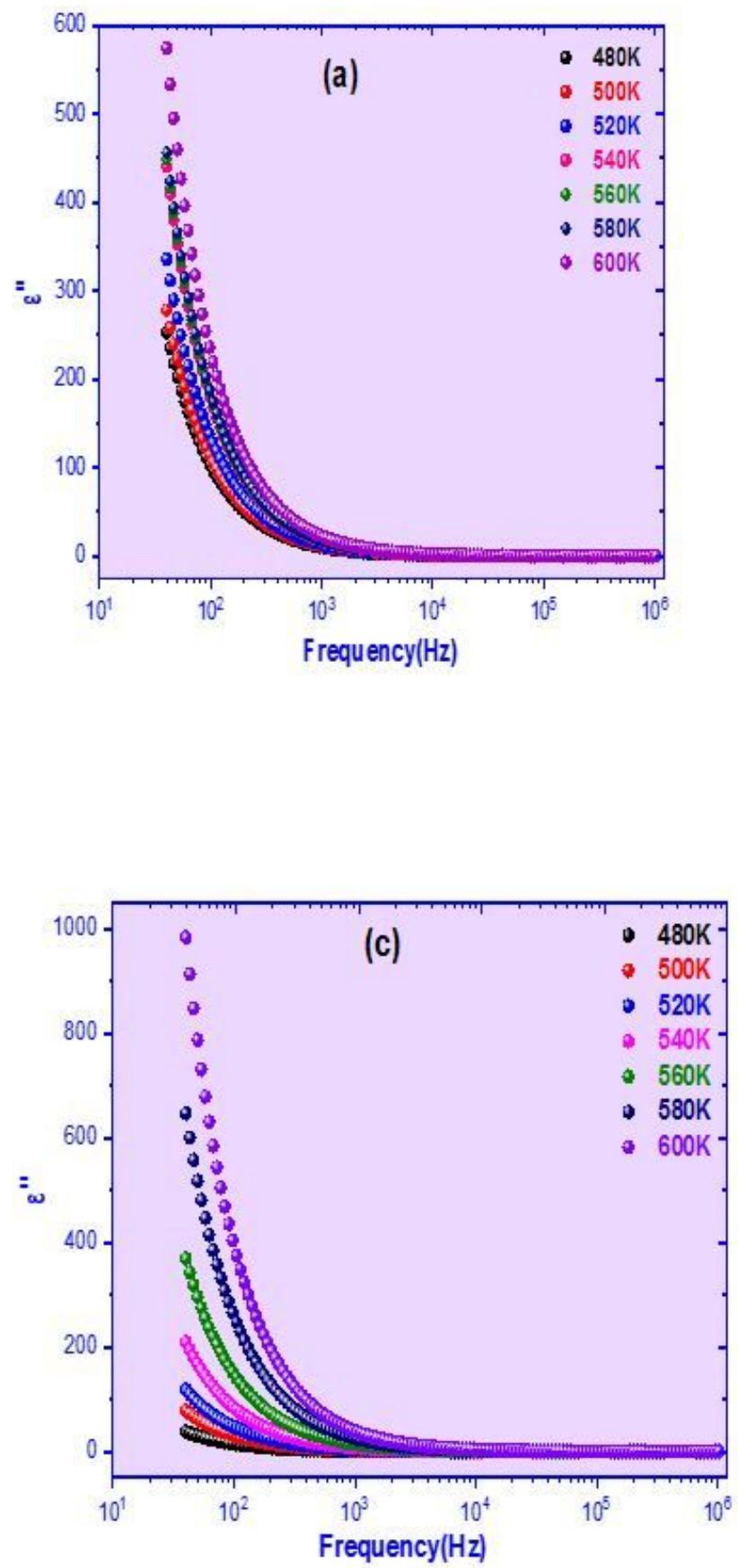
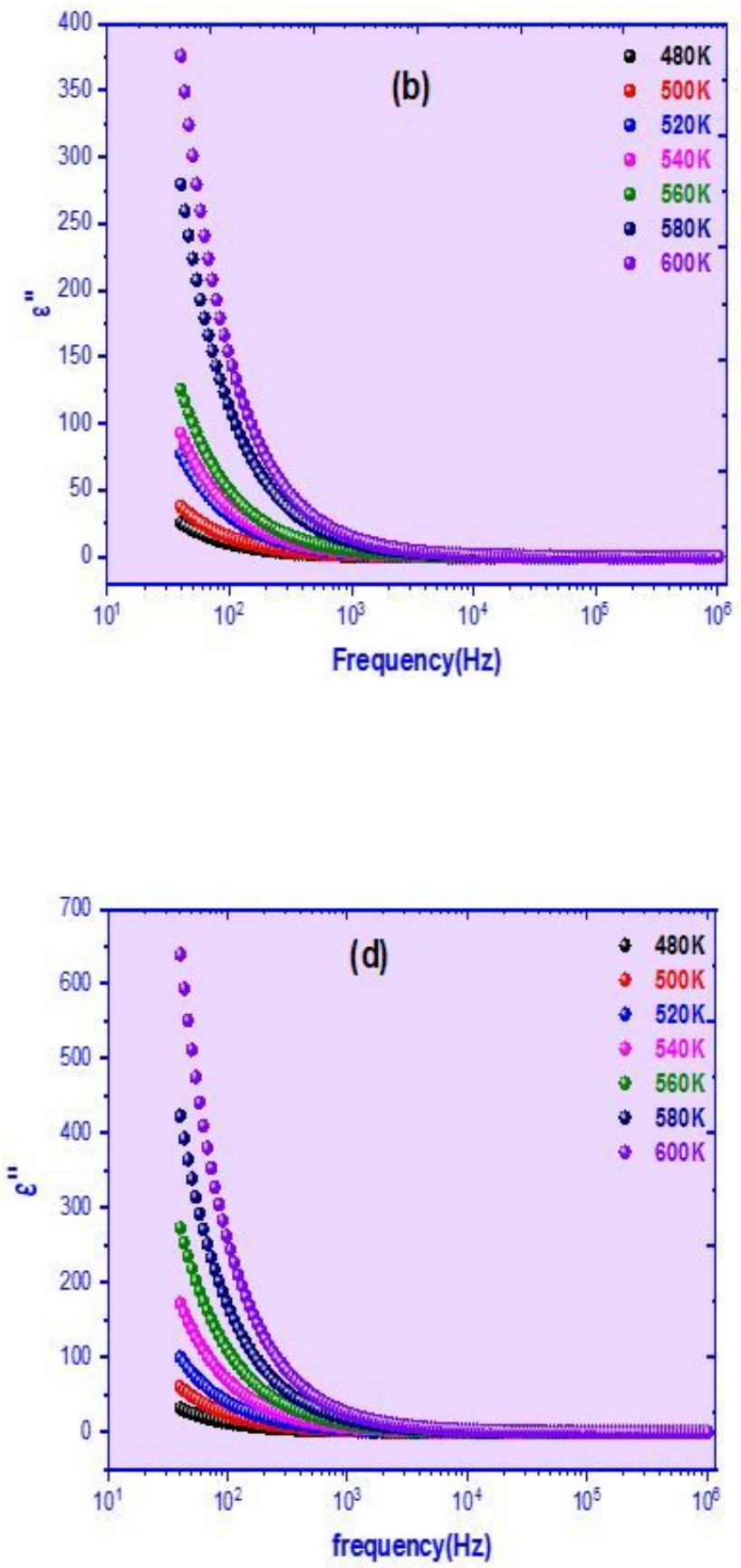

\section{Figure 9}

Frequency dependence of the imaginary part of dielectric permittivity of (a) undoped, (b) $1 \% \mathrm{Zn}$ doped TiO2, (c) 2\% Zn doped $\mathrm{TiO} 2$ and (d) 3\% Zn doped TiO2 

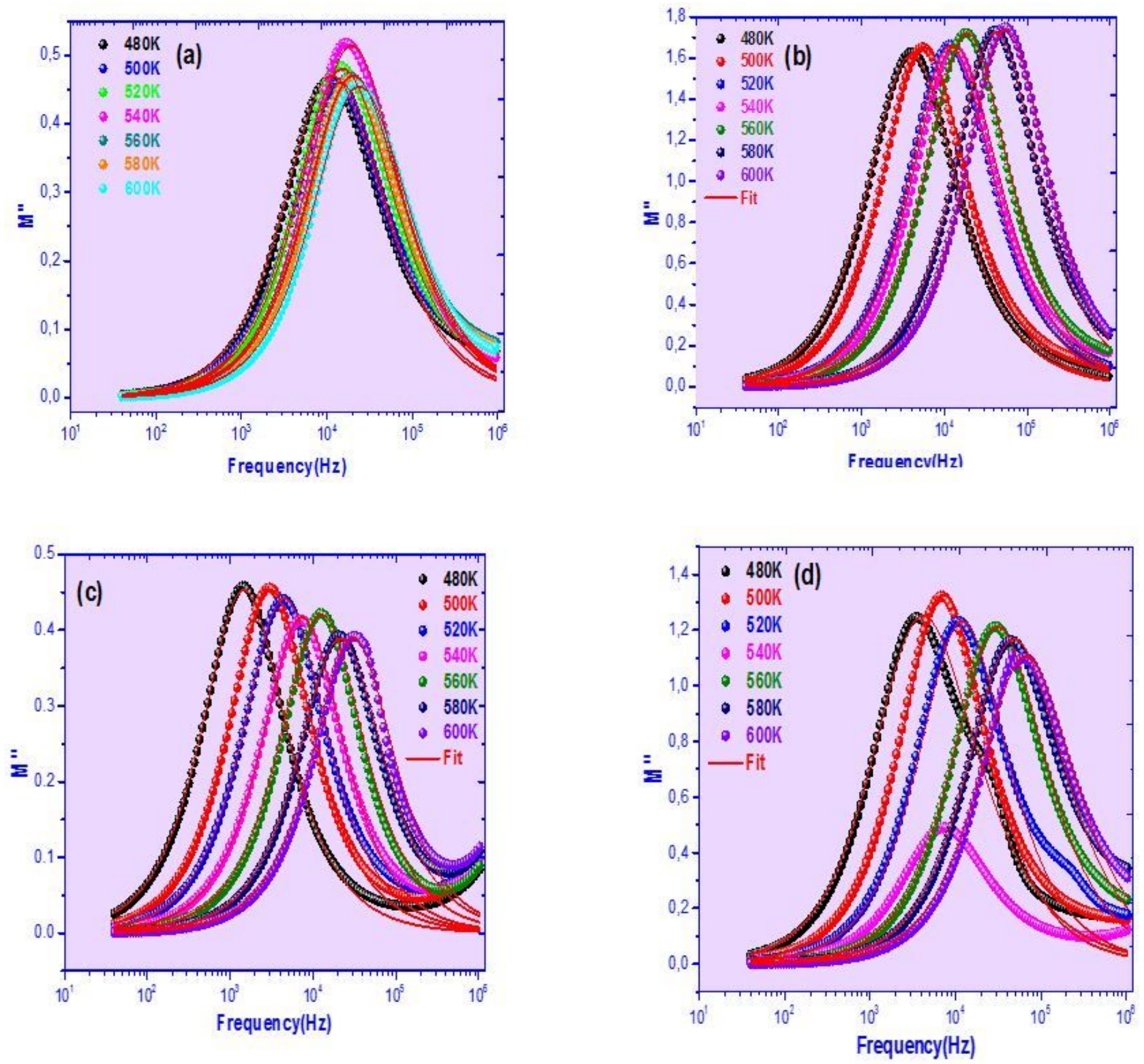

Figure 10

Frequency dependence of the imaginary part M" of the electric modulus for: (a) undoped, (b) Zn1\% doped $\mathrm{TiO} 2$, (c) 2\% $\mathrm{Zn}$ doped $\mathrm{TiO} 2$ and (d) $3 \% \mathrm{Zn}$ doped $\mathrm{TiO} 2$, as a function of temperature 

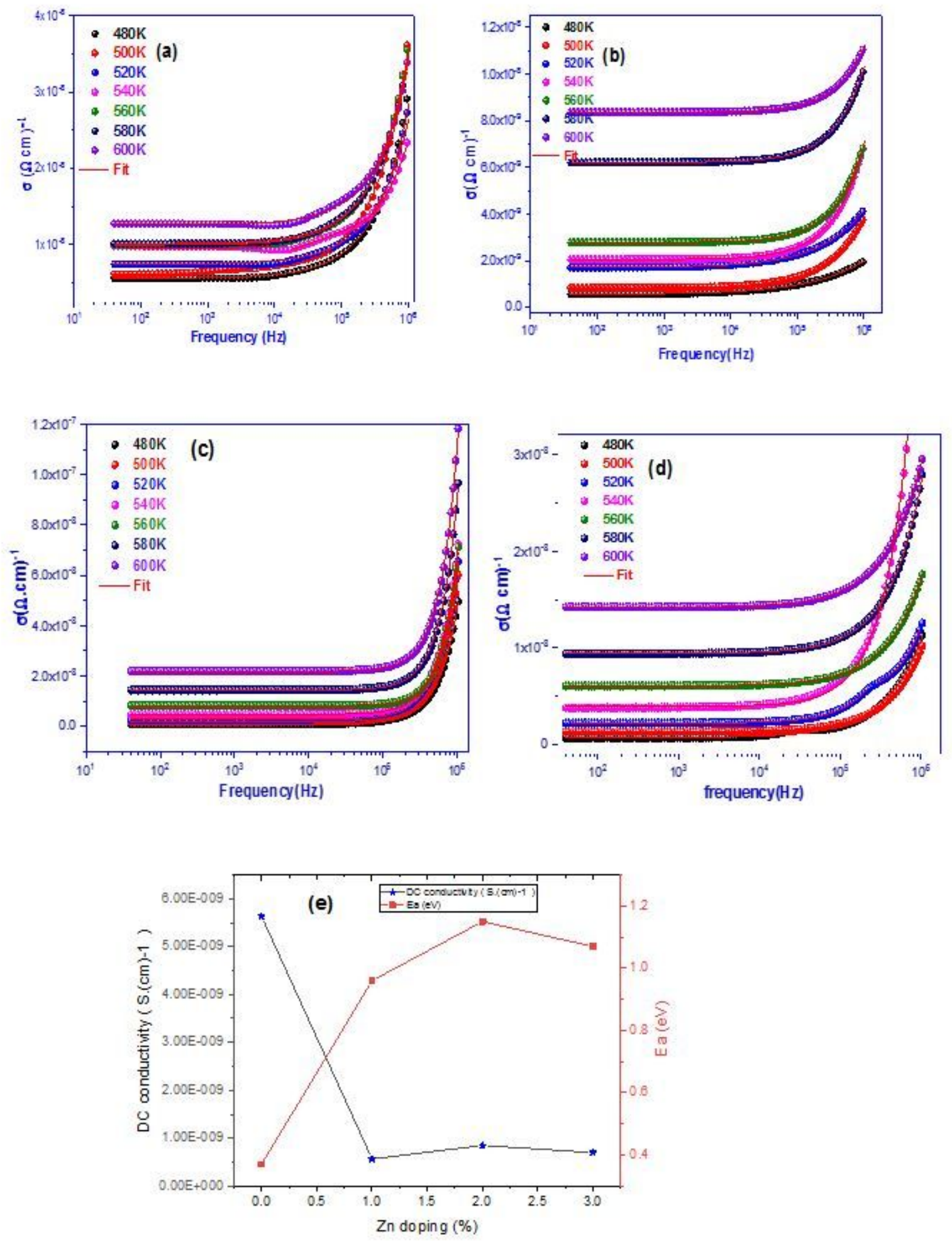

\section{Figure 11}

Frequency dependence of the AC conductivity for (a) undoped, (b) Zn1\% doped TiO2, (c) Zn2\% doped $\mathrm{TiO} 2$ and (d) Zn3\% doped TiO2, as a function of temperature, and (e) the dc conductivity at $480 \mathrm{~K}$, as well as its activation energy vs $\mathrm{Zn}$ doping 

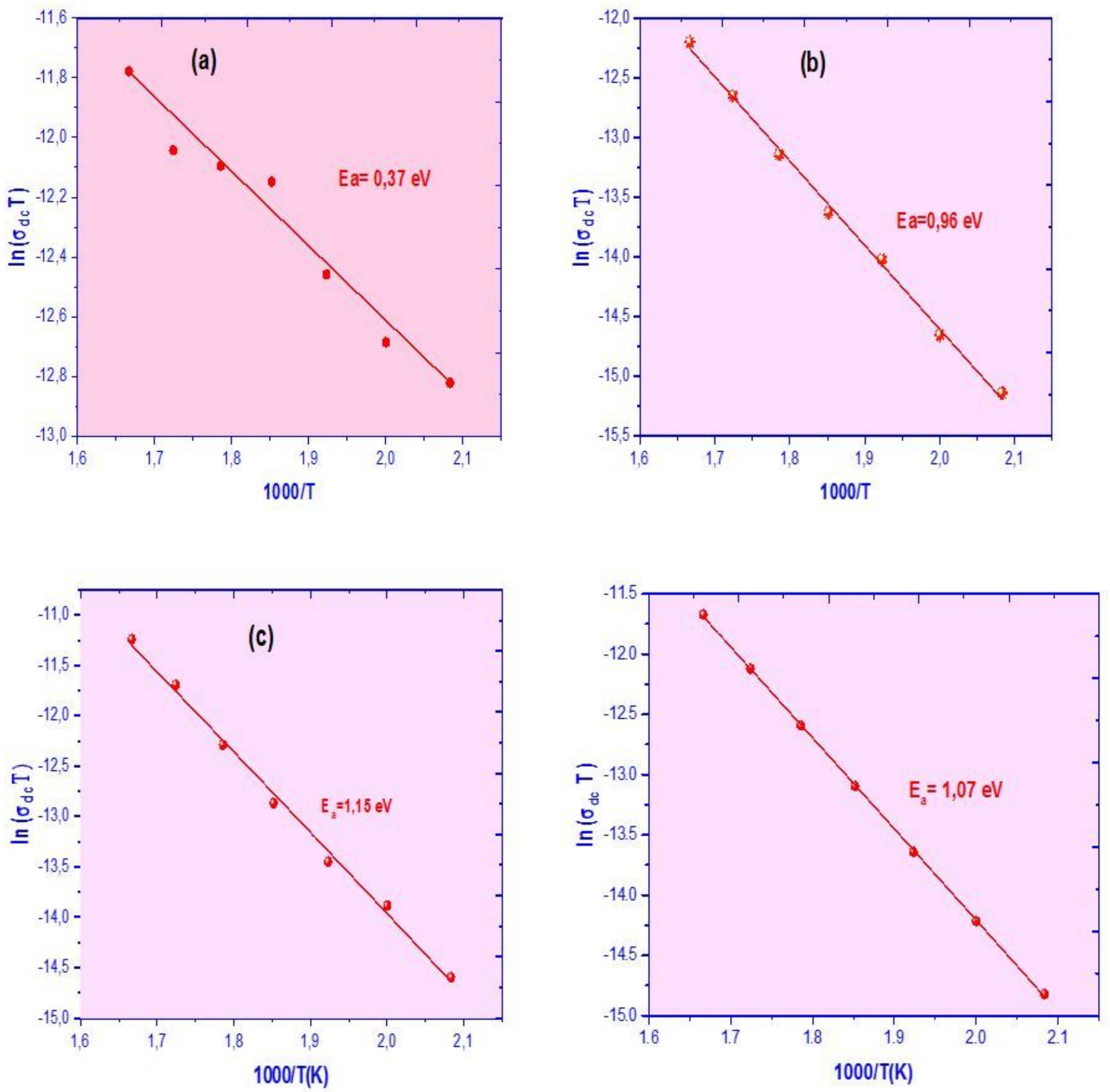

Figure 12

The evolution of ( $\operatorname{Ln}(\sigma d c \mathrm{~T})$ ) versus reciprocal temperature for (a) undoped, (b) 1\% $\mathrm{Zn}$ doped TiO2, (c) 2\% Zn doped $\mathrm{TiO} 2$ and (d) 3\% $\mathrm{Zn}$ doped $\mathrm{TiO} 2$ 

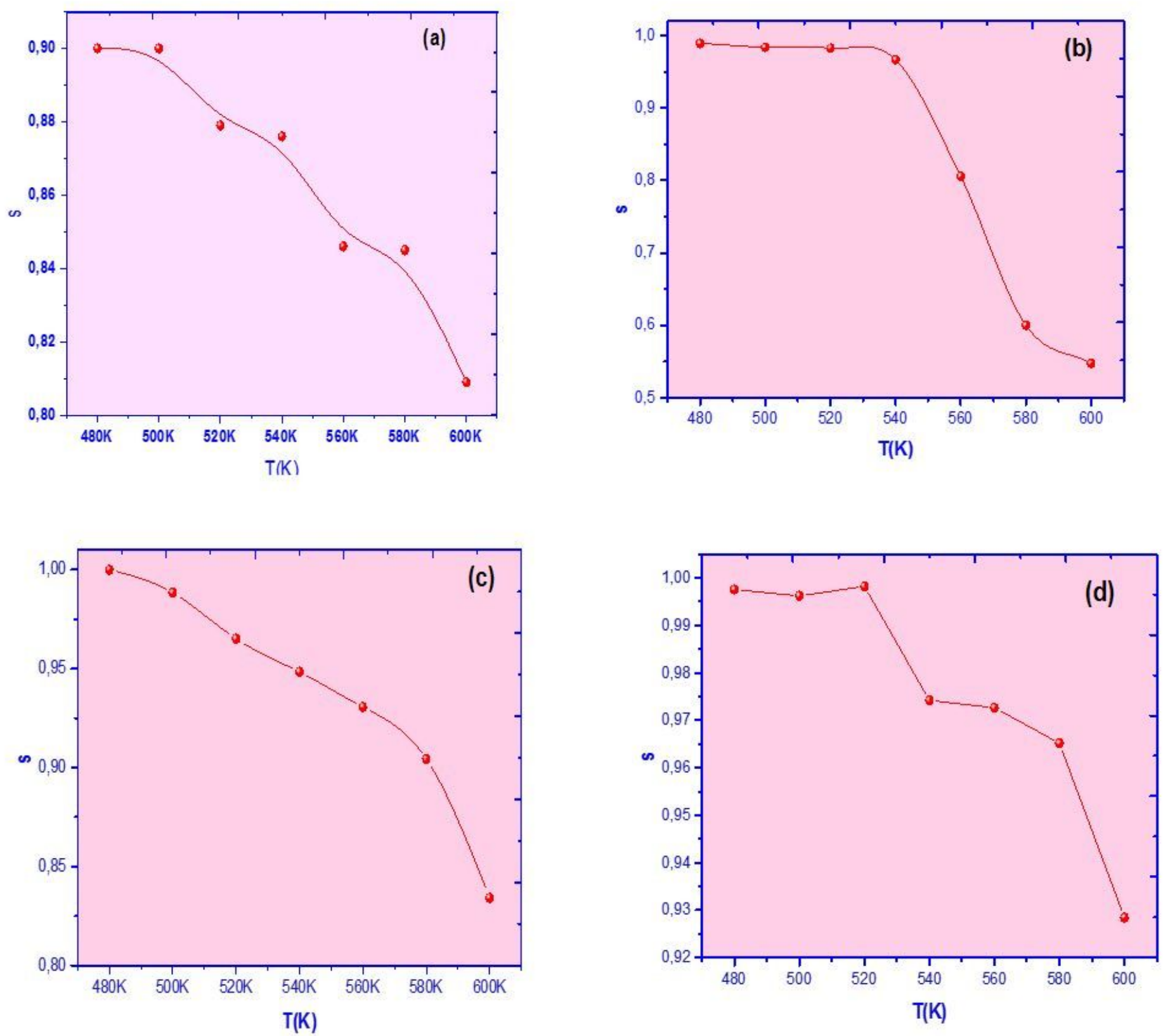

Figure 13

Variation of $\mathrm{s}$ as a function of temperature for (a) undoped, (b) $1 \% \mathrm{Zn}$ doped TiO2, (c) 2\% $\mathrm{Zn}$ doped TiO2 and (d) 3\% Zn doped TiO2 

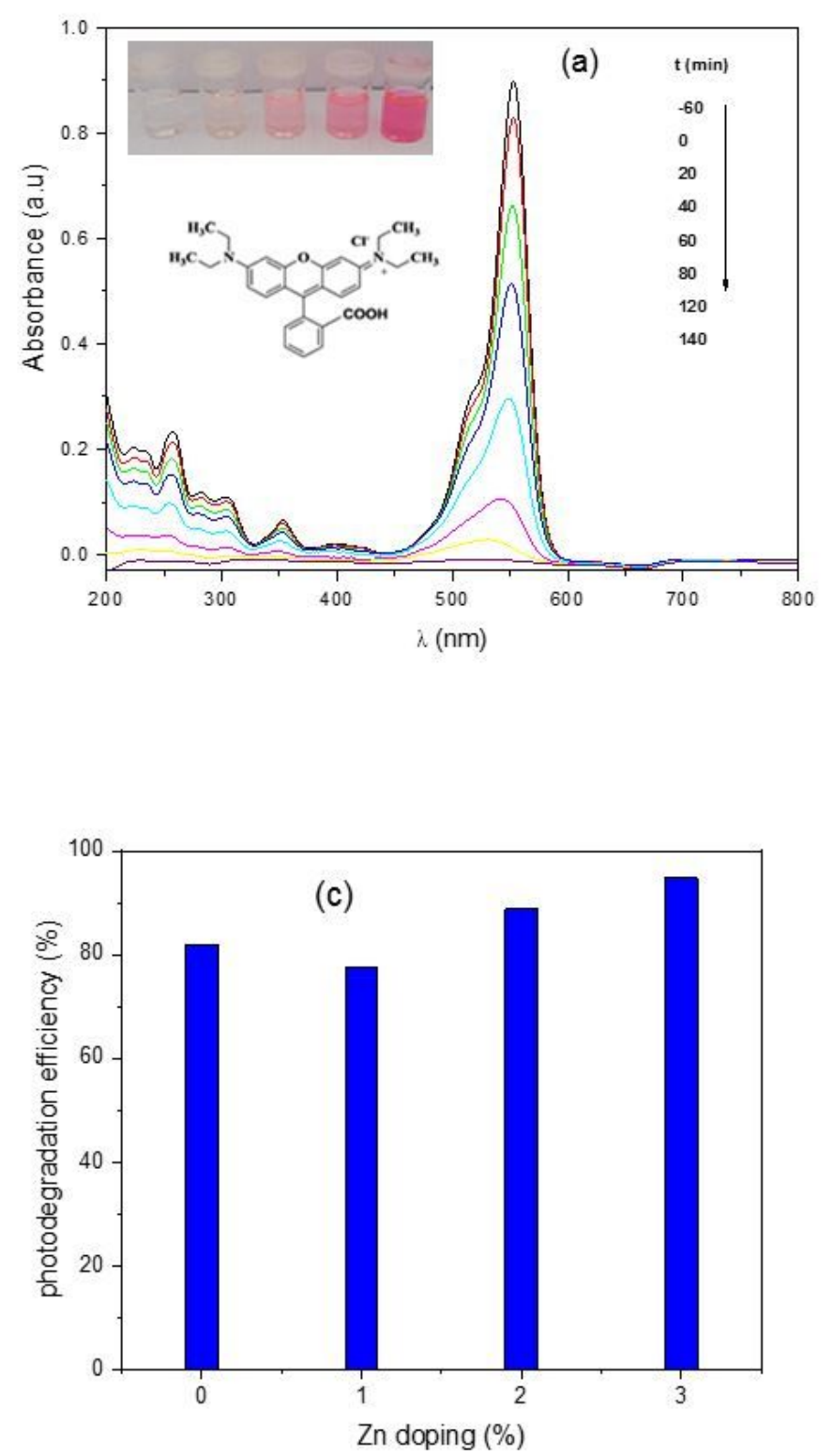
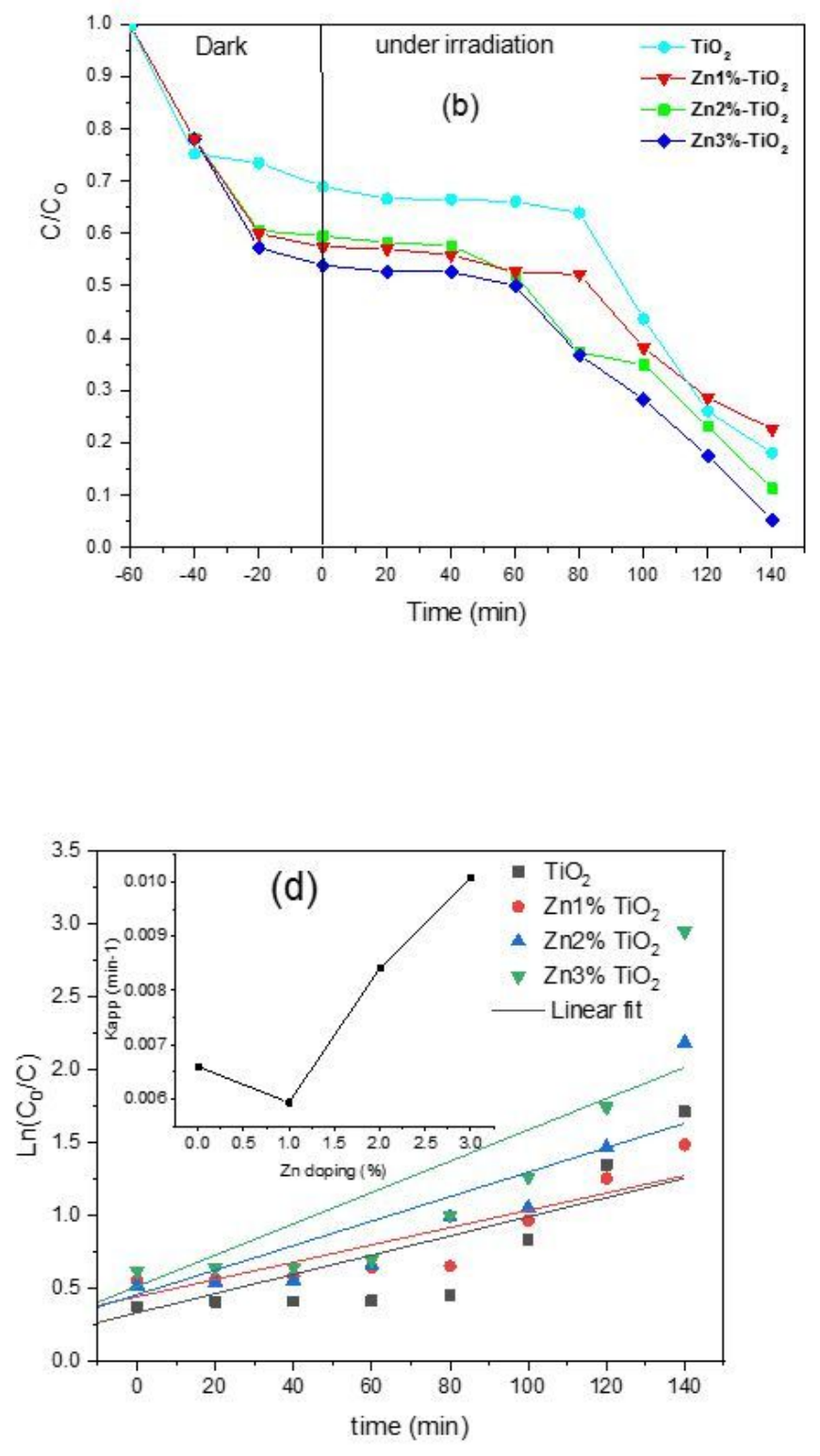

\section{Figure 14}

The variation as a function of the irradiation time of (a) absorbance of RhB solution with $\mathrm{TiO} 2$ nanopowder (b) $\mathrm{C} / \mathrm{CO}$ ratio, (c) photodegradation efficiency after 140mins under UV irradiation, (d) $\operatorname{Ln}(\mathrm{CO} / \mathrm{C})$ 